\title{
A systematic review of real-world evidence of the management of macular oedema secondary to branch retinal vein occlusion
}

\author{
Juan Lyn Ang ${ }^{1} \cdot$ Sarah Ah-Moye ${ }^{1} \cdot$ Leah N. Kim² ${ }^{2}$ Vuong Nguyen ${ }^{2} \cdot$ Adrian Hunt $\mathbb{D}^{2} \cdot$ Daniel Barthelmes ${ }^{2,3} \cdot$ \\ Mark C. Gillies ${ }^{2} \cdot$ Hemal Mehta ${ }^{1,2}$
}

Received: 9 July 2019 / Revised: 19 February 2020 / Accepted: 24 March 2020 / Published online: 20 April 2020

(c) The Author(s), under exclusive licence to The Royal College of Ophthalmologists 2020

\begin{abstract}
This review assessed the real-world evidence of the management of macular oedema secondary to branch retinal vein occlusion (BRVO). A meta-analysis of 2530 eyes from 48 real-world studies of therapies for macular oedema secondary to BRVO was conducted. Baseline characteristics, visual, anatomical and safety outcomes were recorded. The weighted mean and weighted estimates from random-effects models were calculated for visual acuity (VA) and central subfield thickness (CST) changes at 6, 12 and 24 months. Primary outcome was change in VA (logMAR letters) at 12 months. Study quality was assessed using the quality appraisal checklist for case series developed by Institute of Health Economics. The mean baseline VA for the pooled data was $54.0(51.5,56.5)$ letters and the mean baseline CST was $501.3(483.5,519.1) \mu \mathrm{m}$. The random-effects estimate for mean $(95 \% \mathrm{CI})$ change in VA was $14.6(12.5,16.7)$ letters at 12 months $(n=1727)$. The random-effects estimate for mean $(95 \% \mathrm{CI})$ change in CST was $-181.7(-230.7,-132.7) \mu \mathrm{m}$ at 12 months $(n=1325)$. The quality of studies varied considerably. Ocular and systemic adverse events were discussed in $79 \%$ and $42 \%$ of treatment arms respectively, with possible under-reporting. Visual and anatomical gains achieved in the real-world for anti-VEGF therapy were not as impressive as seminal RCTs, possibly due to reduced injection frequency in the real world and differences in baseline characteristics. There is an urgent need for consensus on the minimum efficacy, treatment burden and safety data to collect to strengthen the real-world evidence base.
\end{abstract}

\section{Introduction}

The leading cause of vision impairment in branch retinal vein occlusion (BRVO) is persistent macular oedema, which if left untreated can permanently disrupt the macular architecture [1]. There are a range of treatments currently available for managing macular oedema secondary to

Supplementary information The online version of this article (https:// doi.org/10.1038/s41433-020-0861-9) contains supplementary material, which is available to authorized users.

Hemal Mehta

HM@cantab.net

1 Ophthalmology Department, Royal Free London NHS Foundation Trust, London, UK

2 Macular Research Group, Save Sight Institute, University of Sydney, Sydney, NSW, Australia

3 Department of Ophthalmology, University Hospital Zurich \& University of Zurich, Zurich, Switzerland
BRVO that have been investigated in randomised controlled trials (RCTs). The question is whether these RCT results can be replicated in the real world.

The Branch Vein Occlusion Study (BVOS) was a landmark trial published in 1984 assessing macular grid laser for BRVO. It established grid laser as the first-line therapy of macular oedema secondary to BRVO for subsequent decades. More participants in the grid laser group (65\%) had ten or more letter vision gain at 36 months compared with the placebo group (37\%) at 36 months [2].

Intravitreal corticosteroid therapies, which inhibit numerous local inflammatory modulators and vascular endothelial growth factor (VEGF), then emerged [3]. The Standard Care versus Corticosteroids for Retinal Vein Occlusion (SCORE) study found no difference in visual acuity (VA) and macular centre point thickness at 12 months between patients treated with 1 and $4 \mathrm{mg}$ triamcinolone and grid photocoagulation, but there were higher rates of adverse events particularly elevated intraocular pressure (IOP) and cataract in the group treated with $4 \mathrm{mg}$ of triamcinolone [4]. 
Intravitreal dexamethasone implants for BRVO were evaluated as part of the Global Evaluation of implantable dexamethasone in retinal vein occlusion with macular edema (GENEVA) trial which reported a 15 letter VA gain at 180 days in $41 \%$ of the dexamethasone implant $0.7 \mathrm{mg}$ group, $40 \%$ in the $0.35 \mathrm{mg}$ group and $23 \%$ in the sham group [5]. A 6-month extension of the GENEVA study examined safety outcomes at 12 months [6]. Only combined BRVO and CRVO data were reported; there was greater cataract progression in the $29 \%$ of eyes re-treated with dexamethasone implants compared with $6 \%$ of eyes that received a single implant [6]. IOP-lowering medications were started in $26 \%$ of eyes in the initial dexamethasone treatment groups and in additional $10 \%$ of those who had a second implant [6].

More recently intravitreal anti-VEGF therapies have become available and are often first-line treatment for macular oedema secondary to BRVO [7]. Ranibizumab has been the anti-VEGF agent most widely investigated in RCTs, first in the Branch Retinal Vein Occlusion: Evaluation of Efficacy and Safety (BRAVO) study [8, 9], then in HORIZON [10], an open-label, single-arm extension trial for BRAVO and other phase III ranibizumab studies and subsequently the extended follow-up of patients with macular oedema due to bRanch rETinal vein occlusion or centrAl retinal veIn occlusioN previously treated with intravitreal ranibizumab (RETAIN) study [11]. Overall, patients who received ranibizumab had greater visual gains and greater central foveal thickness (CFT) reductions compared with patients who received sham treatment at 6 months [8] and after crossover to ranibizumab, the sham group experienced visual gains but not to the same level of improvement as other groups which were treated with ranibizumab early on [9]. This reinforced the importance of initiating treatment early. Ranibizumab was compared against macular laser in the BRIGHTER study, where ranibizumab groups had superior outcomes compared with the laser monotherapy group at 6 months and 24 months $[12,13]$. Overall, the BRIGHTER study results suggested that addition of laser did not lead to better visual outcomes and did not reduce the number of ranibizumab injections (11.4 vs. $11.3 ; p=0.4259$ ) [13].

The VIBRANT study was a randomised, doublemasked phase III trial that evaluated whether aflibercept was superior to grid laser for macular oedema secondary to BRVO [14, 15]. Monthly aflibercept led to greater vision gains and central retinal thickness (CRT) reduction at 6 months compared with the macular laser arm [14]. At 24 weeks the laser arm was allowed rescue therapy with aflibercept. The CRT and BCVA improved at 52 weeks when aflibercept was added, however the improvement was not as great as those eyes treated initially with aflibercept [15].
The MARVEL study was a small trial involving 75 participants compared intravitreal injections of bevacizumab and ranibizumab. The 6-month findings suggested no significant difference in visual outcomes between the drugs using the 'as required regime', with an average of three to four injections needed in the first 6 months [16]. The Comparison of AntiVEGF Agents in the Treatment of Macular Edema from Retinal Vein Occlusion Trial (CRAVE) randomised 98 patients to ranibizumab or bevacizumab every month for 6 months and reported no difference in functional and anatomical outcomes between treatment arms in the short term [17]. The BRVO study, an RCT comparing $1.25 \mathrm{mg}$ bevacizumab against $0.5 \mathrm{mg}$ ranibizumab delivered monthly to 277 patients reported no difference in visual outcomes at 6 months [18].

Ranibizumab was compared against dexamethasone implants in the COMRADE-B [19] trial and a study by Bandello and colleagues [20] but the trials employed different treatment regimens (see Table 1). COMRADE-B reported greater visual acuity gains in patients treated with ranibizumab compared with dexamethasone over a 6-month study period [19] whereas Bandello and colleagues [20] reported no significant difference in visual outcomes between the arms, though acknowledged their study was under-powered [20].

Other treatment options that have been explored for treatment of macular oedema secondary to BRVO include vitrectomy with internal limiting membrane peeling [21] or arteriovenous sheathotomy [22, 23], and systemic haemodilution [24]. These treatment options are not discussed further here as there is not enough evidence from RCTs to consider them current mainstream therapy.

There are multiple reviews assessing the RCT evidence for these treatment options, including Cochrane reviews $[25,26]$ and American Academy of Ophthalmology guidelines [27]. A summary of findings from seminal RCTs is presented in Table 1. Although RCTs are generally considered the 'gold standard' for providing evidence for efficacy and safety of therapies, results from these selected populations may not always be generalisable to the real world [28]. Real-world studies can also inform us as to the long-term safety and efficacy of drugs beyond the timeframe of the RCTs. They can also highlight different outcomes that reflect limitations on drug availability and reimbursement in different healthcare systems [28]. Although there may be a lower level of certainty on the evidence hierarchy compared with RCTs, real-world data may have better external validity and can complement findings from RCTs [28, 29].

Here, we present a systematic review of real-world evidence of the management of macular oedema secondary to BRVO to inform clinicians and identify gaps in the evidence base that could be addressed in future real-world studies. 


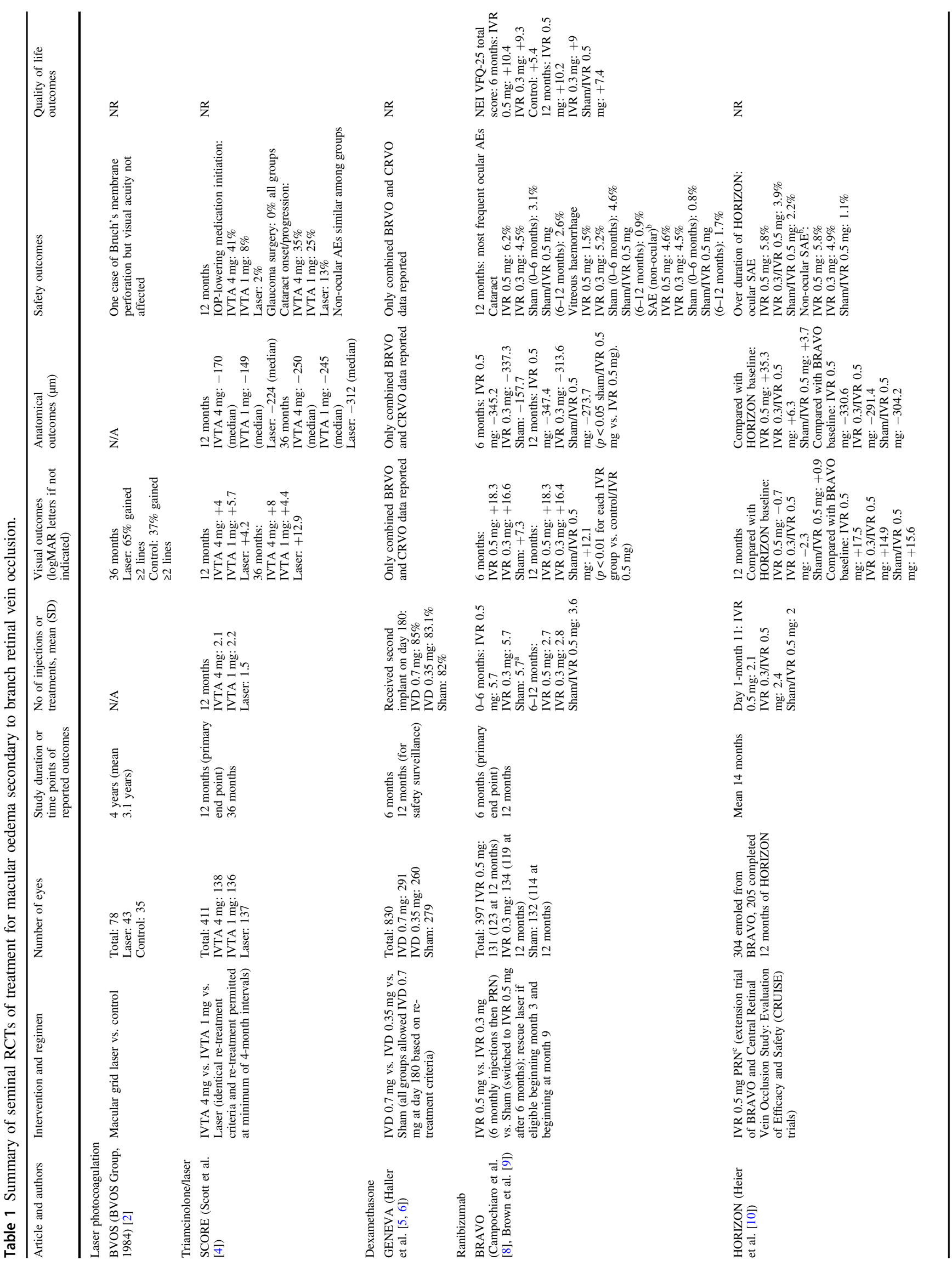




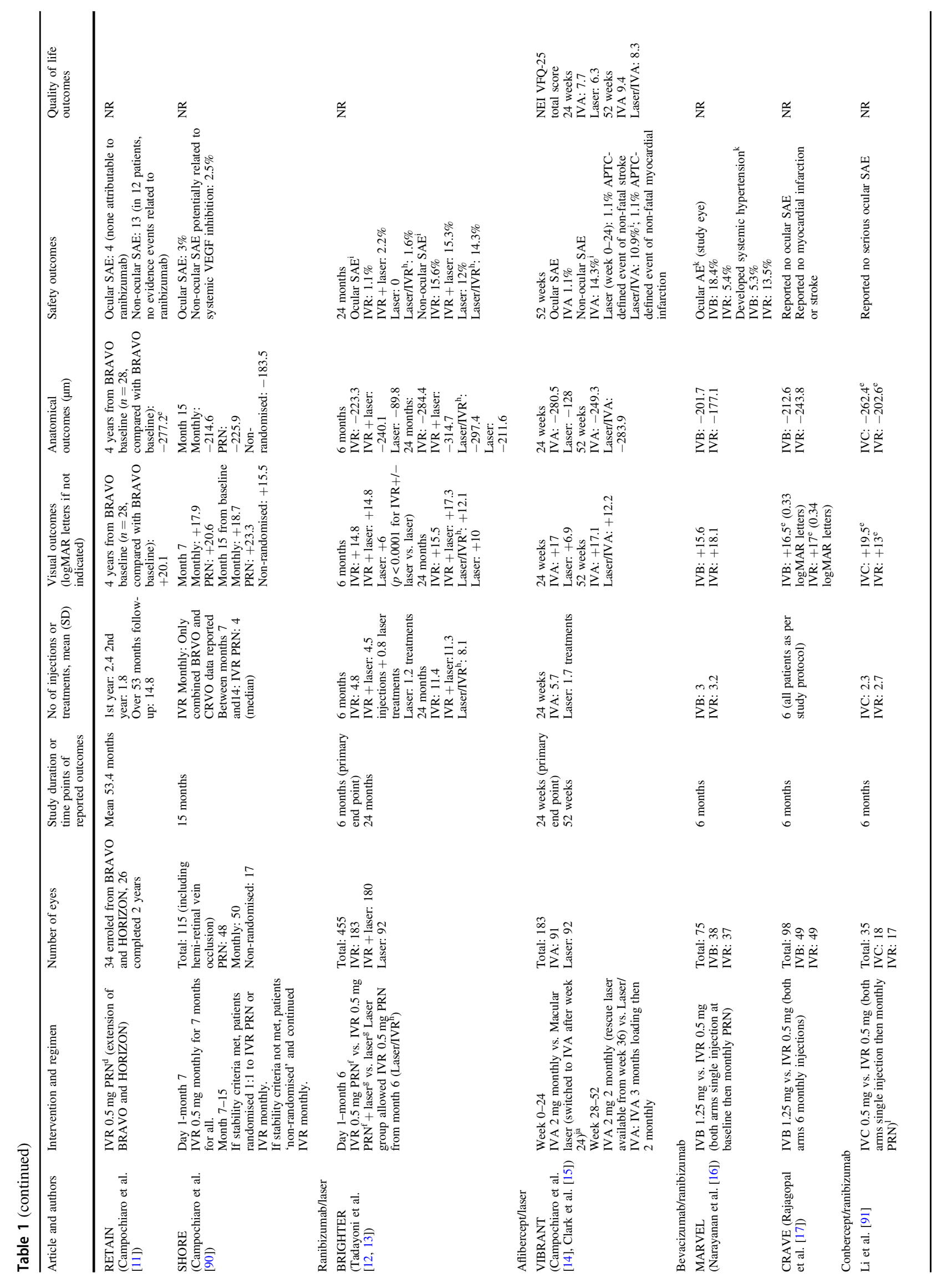




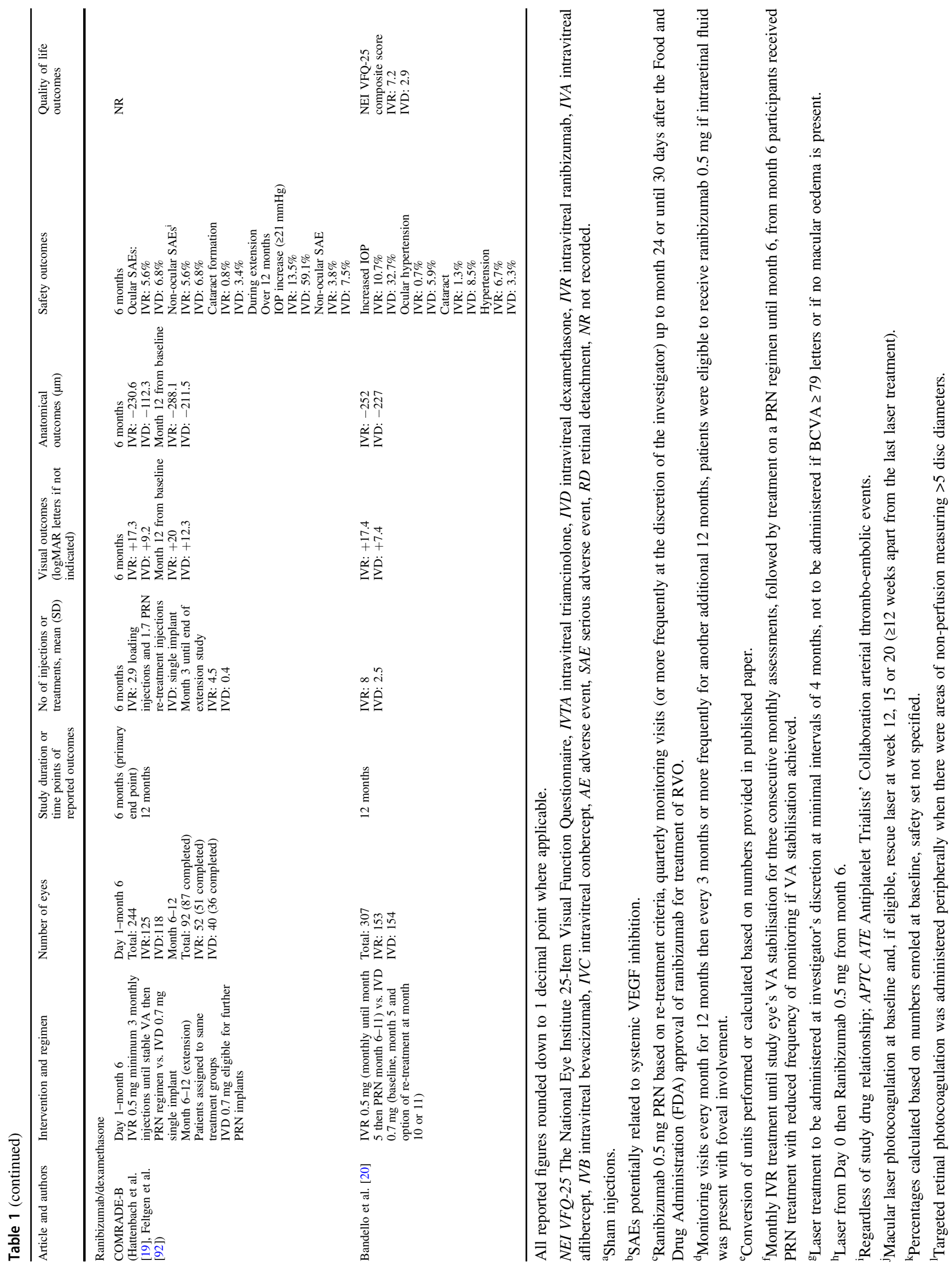




\section{Methods}

\section{Search strategy}

A systematic search of the literature was conducted on 2 September 2019, using Medline, Embase and PubMed databases by two authors (JLA and LK) independently to identify potentially eligible studies. Further references were identified by manually searching included articles and consulting experts in the field. The following multipurpose search terms were used which looked in the Title, Original Title, Abstract, Subject Heading, Floating Sub-heading, Keywords, Name of Substance, Supplementary Concept Words, Synonyms and Unique Identifier fields: 'cystoid macular oedema' OR 'cystoid macular edema' OR 'CME' OR 'CMO' OR 'cystoid macula oedema' OR 'cystoid macula edema' OR 'macular oedema' OR 'macular edema'; 'branch retinal vein occlusion' OR 'BRVO'; 'management' OR 'therapies' OR 'therapy' OR 'treatments' OR 'treatment'. The following medical subject heading terms were also used: 'macular edema', 'treatment outcomes'.

\section{Study selection}

Real-world studies of therapies for macular oedema secondary to BRVO published between 1 January 2009 and 2 September 2019 were included. Assessment of eligibility was performed independently by two authors (JA and SAM) and any disagreements were discussed with a senior author (HM). Real-world studies have inherent noise, and therefore we have chosen to include only studies with at least a treatment arm reporting 25 eyes at 6 months ( \pm 2 weeks) follow-up from commencement of intervention. Studies were included if they reported visual outcomes for patients regardless of whether they were treatment-naïve or not. The main interventions for macular oedema secondary to BRVO comprised macular lasers, intravitreal corticosteroids and intravitreal anti-VEGF agents.

RCTs and their post hoc analyses were excluded as the focus of this review was real-world evidence. Studies were excluded for the following reasons: (a) if the BRVO results could not be differentiated from central retinal vein occlusion (CRVO) results, (b) if it was not possible to identify which treatment was delivered to achieve the visual acuity outcome, (c) non-interventional studies, (d) studies investigating switching therapies, (e) studies that did not report on baseline and post-intervention visual acuity which we consider core data, (f) studies that only presented subgroups and not the full dataset of interventions, (g) follow-up data at no clear time-point and (h) conflicting data reported. A list of excluded studies along with corresponding reasons for exclusion is provided (available as online supplement, Supplementary Table A).

\section{Data extraction and synthesis}

Articles were reviewed and data were extracted by two authors independently (JLA and SA-M). Any discrepancies were discussed with a third senior author (HM) to reach consensus. The following data were extracted from each report:

(1) Study design

(2) Country or region

(3) Number of eyes

(4) Mean age of patients

(5) Percentage of female patients

(6) Treatment-naïve status

(7) Treatment regimen and dosage

(8) Time to commencement of treatment

(9) Reporting of ischaemic or non-ischaemic status at the macula and in the periphery at baseline

(10) Reporting of presence of subretinal fluid (SRF) at baseline

(11) Reporting of hypertension, diabetes mellitus and smoking status of patients at baseline

(12) Inclusion or reporting of high-risk group at baseline e.g., patients with history of cardiovascular disease or cerebrovascular disease

(13) Reporting of percentage of eyes that were pseudophakic at baseline

(14) Visual acuity at baseline, 6 months, 12 months and 24 months after commencing treatment

(15) Central subfield thickness at baseline, 6 months, 12 months, 24 months after commencing treatment

(16) Mean number of intravitreal injections administered over the follow-up period

(17) Macular laser treatment administered over the followup period

(18) Need for retinal laser therapy for neovascularisation

(19) Need for rescue therapy

(20) Total number of ocular adverse events

(21) Mean number of visits over follow-up period

(22) Ocular adverse events: number of cases of endophthalmitis, neovascularisation of disc (NVD), neovascularisation elsewhere (NVE), neovascularisation of iris/angle (NVI/A), IOP increase requiring IOP-lowering therapy, rubeotic glaucoma, traumatic cataract, cataract progression, retinal detachment, macular changes affecting vision (e.g. epiretinal membrane, whole pigment clumping, atrophy) and vitreous haemorrhage

Study quality was assessed using the quality appraisal checklist for case series developed by Institute of Health Economics (IHE) [30], as this was the preferred tool by National Institute for Health and Care Excellence (NICE) [31]. This was conducted independently by two authors 
(JLA and SA-M) and any discrepancies were discussed with a senior author (HM) to reach consensus. The assessment was based on aspects of study objective, study design, study population, intervention and co-intervention, outcome measure, statistical analysis and results and conclusion [31], and criteria for aspects of the checklist were customised for the ophthalmology studies included in this review (available as online supplement, Supplementary Table B). Scores were assigned to studies based on this assessment for ease of comparison. Eyes were said to have entered the study at a similar point of the disease if standard deviations (SD), inter-quartile ranges or equivalent measures were reported to be $\leq 6$ months or if studies specified that eyes entered at a similar point e.g., newly diagnosed or acute or chronic stages of macular oedema [9]. The rationale for using 6 months as a cut-off comes from the finding of BRAVO, in which patients in the control arm who experienced a delay in ranibizumab treatment by 6 months did not achieve the same visual gains as the patients who received ranibizumab from the start [9].

\section{Assumptions}

If a study was not specified as single or multi-centre in nature, or if only one location was specified, it was assumed to be a single-centre study. If a study only reported the number of patients, it was assumed that one eye per patient was included. Visual acuity scores were converted to logMAR letters for consistency. The change and absolute visual acuities and CST were calculated where they were not supplied. The term CST was used as a blanket term to include CFT, central macular thickness, central subfield thickness and foveal centre point thickness. All numbers were rounded to a single decimal point where applicable. If a proportion of patients were reported to have received any prior treatment, the cohort was assumed to be non-naïve. As there is wide variation in how studies reported the duration before starting treatment, we directly quoted them in the real-world studies summary table. Duration was converted to days if reported in a different unit. When it was uncertain as to whether the location of ischaemia was peripheral or at the macula, this was reported in the summary table. If studies excluded patients with ischaemic BRVO or ischaemic maculae, it was assumed that $0 \%$ of patients had ischaemia at baseline. Only results from time points at which there were 25 or more patients were included in the VA, CST and injection number meta-analyses. When outcomes were reported for different numbers of patients at different time points, the outcomes for 6,12 or 24 month time points were preferentially extracted, even if there were a smaller number of patients due to loss to follow up at these time points. We avoided extracting outcomes for subgroups in included studies, unless it was the only data available. Reported presence of SRF and serous retinal detachment were considered to be equivalent. When dosage was not specified it was assumed that the standard doses were used.

\section{Statistical analysis}

There was a high level of heterogeneity in treatment and patient population between studies. We described the characteristics and quality of each study and their outcomes as specified in our protocol, stratified by treatment arms defined by treatment drug and dose. Parameters described qualitatively were not considered for quantitative metaanalysis. For the purposes of the meta-analyses, the primary outcome was change in VA (logMAR letters) at 12 months. Secondary outcomes included change in VA at 6 and 24 months, change in CST at 6,12 and 24 months and number of treatments over 6, 12 and 24 months. Metaanalyses could only be performed if there was more than one included real-world study of an intervention.

Primary and secondary outcomes were pooled by calculating the mean across all studies weighted according to their total sample size. We also calculated weighted estimates from random-effects models to account for heterogeneity both within and between studies. The inverse-variance method was used to weight studies in the random-effects estimates. Heterogeneity between studies was measured using the $I^{2}$ statistic, with values of $25 \%, 50 \%$ and $75 \%$ denoting low, moderate and substantial heterogeneity, respectively [32].

Mixed-effects meta-regression models were used to estimate and compare outcomes by treatment groups with additional adjustments for age, VA and CST at baseline for estimates of changes in VA and CST.

The mean and standard deviation were estimated when studies only reported the median and first and third quartiles (Q1 and Q3). The mean was estimated as the sum of the median, Q1 and Q3, divided by three [33]. The standard deviation was estimated as Q3 minus Q1, divided by 1.35 [34]. If the standard deviation was not available and could not be derived or estimated from other summary statistics, these values were imputed using multiple imputations and the model results pooled [35, 36].

Analyses were conducted using $\mathrm{R}$ version 3.6.1. The mice package (version 3.6.0) was used for multiple imputations and the metafor package (version 2.1-0) was used to conduct meta-analyses and random-effects models [37].

\section{Results}

\section{Included studies}

The literature search returned a total of 591 articles on Medline, 657 articles on PubMed and 1196 articles on 
Fig. 1 Flowchart of the process of reviewing and selecting articles. The grey boxes indicate the stage of the selection process; $n$ denotes the number of articles included at each stage of the process.

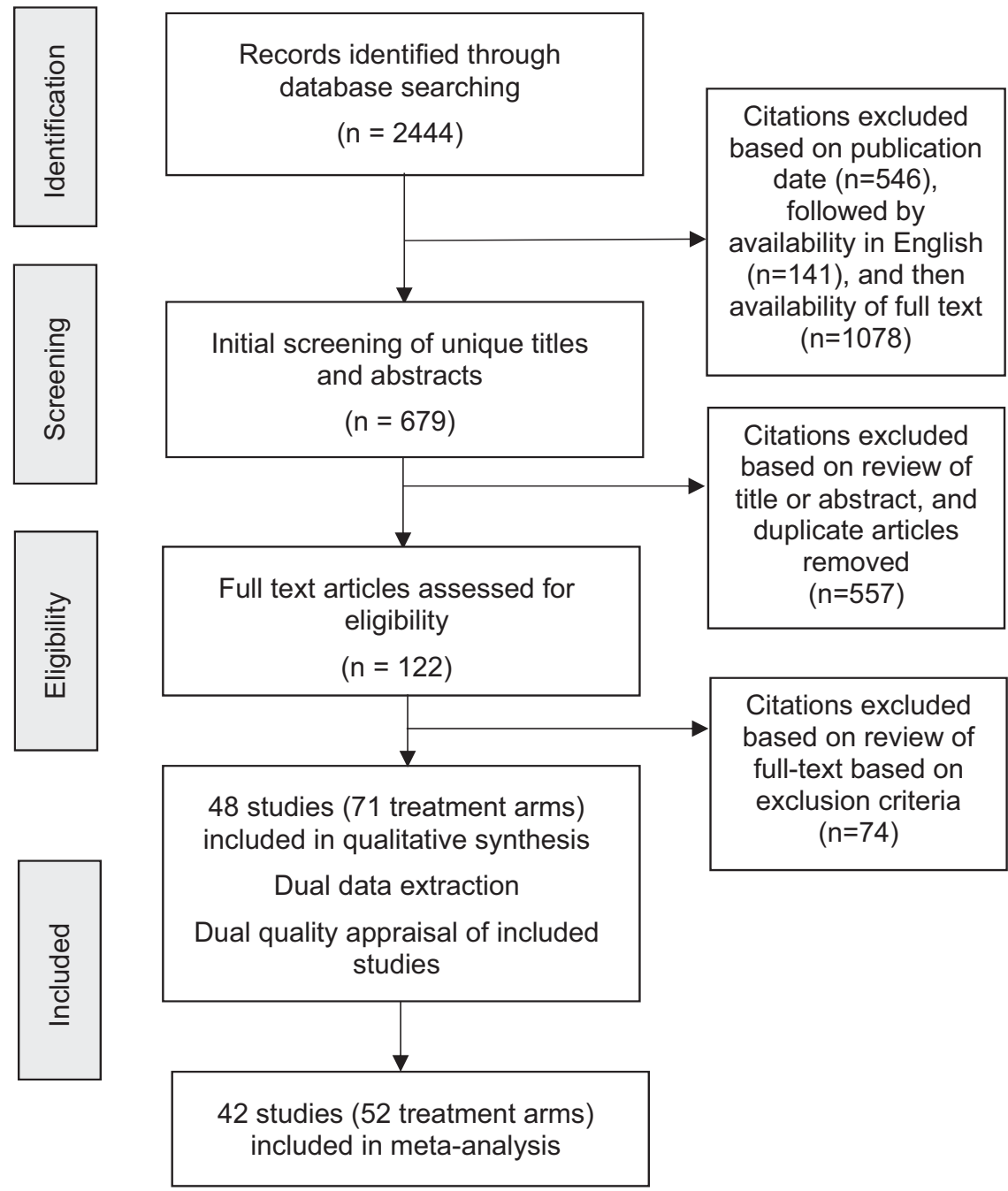

Embase. Based on our inclusion and exclusion criteria, 48 articles published between 1 January 2009 and 2 September 2019 were included. Of these, 42 studies were included in the meta-analyses. There was a total of 2530 eyes with macular oedema across all the studies included. A summary of the review and study selection process is presented in Fig. 1.

\section{Summary tables}

Visual and anatomical outcomes along with treatment burden findings of included real-world studies are presented as an online supplement (Supplementary Table C). The baseline characteristics of all included studies are listed in Table 2. The systemic risk factors and details of additional therapy including lasers reported in studies are presented as online supplements (Supplementary Tables D and E, respectively). There was no quality of life data to report in included studies.

\section{Description and quality evaluation of studies}

The quality of studies as assessed using the adapted IHE critical appraisal checklist is presented as an online supplement (Supplementary Table F). Scores for quality of studies ranged from 10.5 to 17.5 with a maximum of 20 points available. In particular, 24 of the 48 studies had clear reporting of consecutive recruitment while in other studies this was unclear. Eligibility criteria was clearly stated in all but three studies. Of the 48 studies included in this review, only 4 explicitly reported partial masking during CST or BCVA assessment. It was unclear whether the further 44 studies employed masking. Moreover, the feasibility and importance of partial or complete masking in real-world studies have not yet been established.

Loss to follow-up was not consistently reported, with 10 of the 48 studies not reporting on loss to follow-up. Visual and anatomical outcomes were measured appropriately in the majority of studies, but it was noted that a variety of 


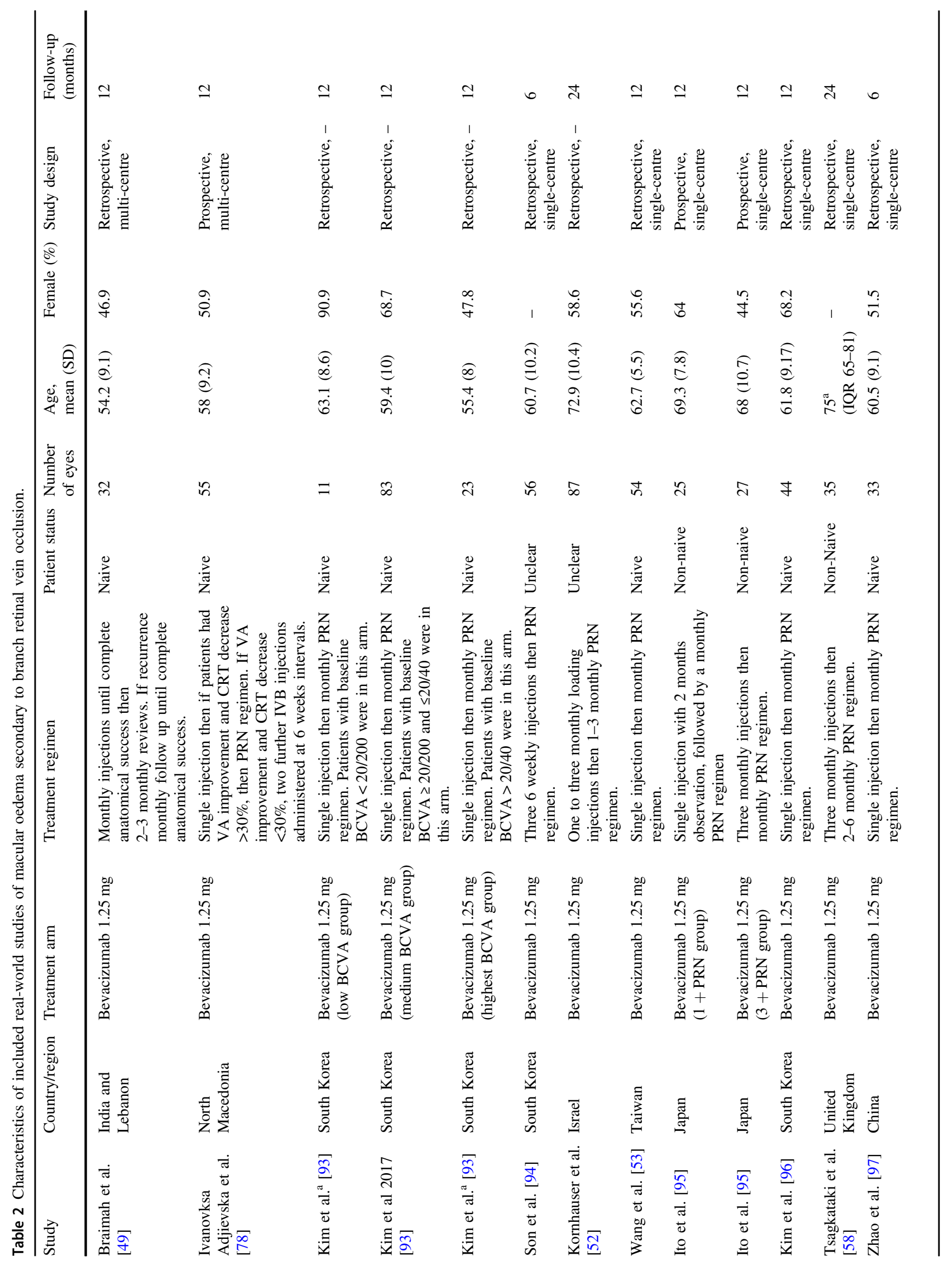




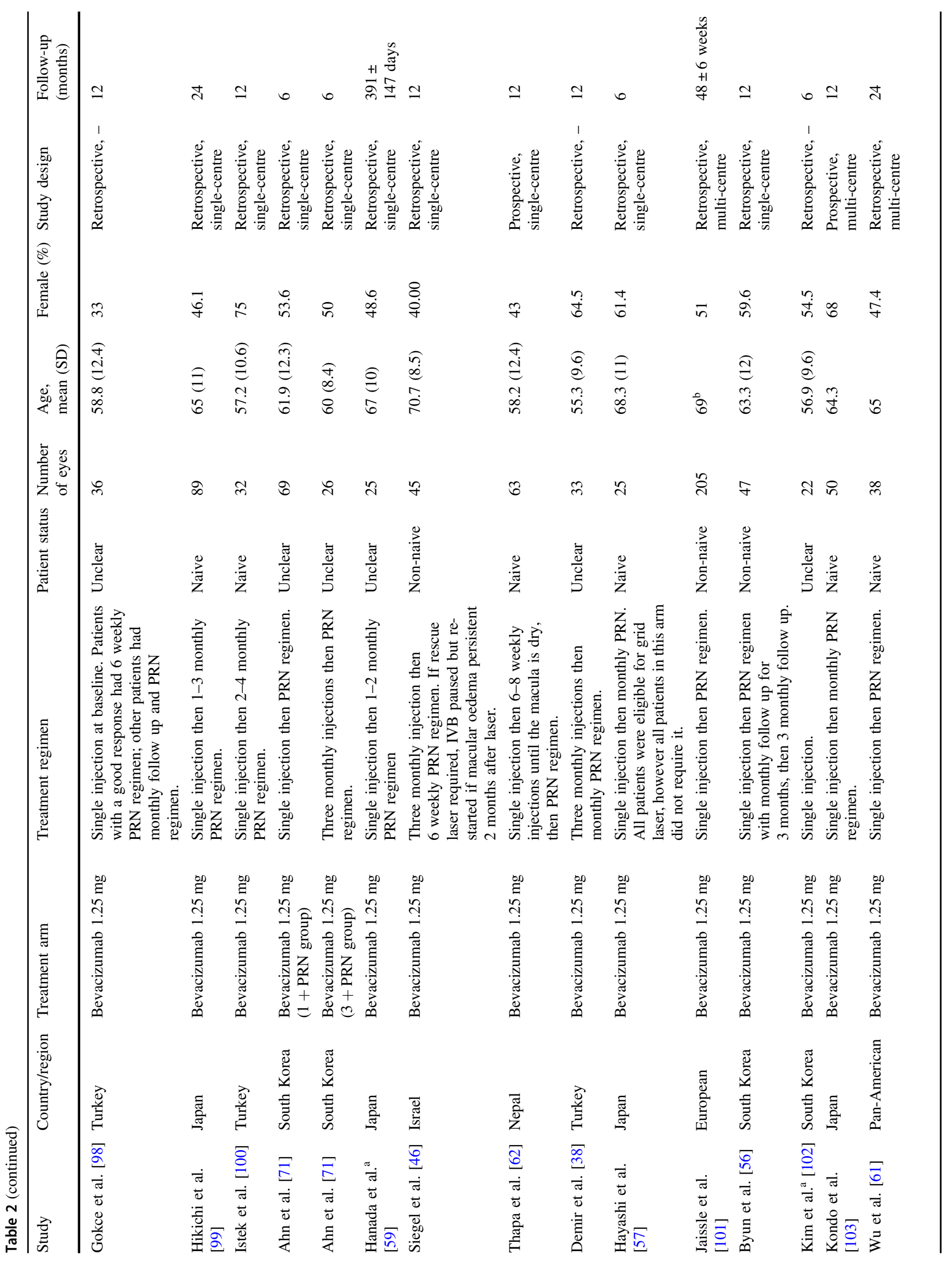




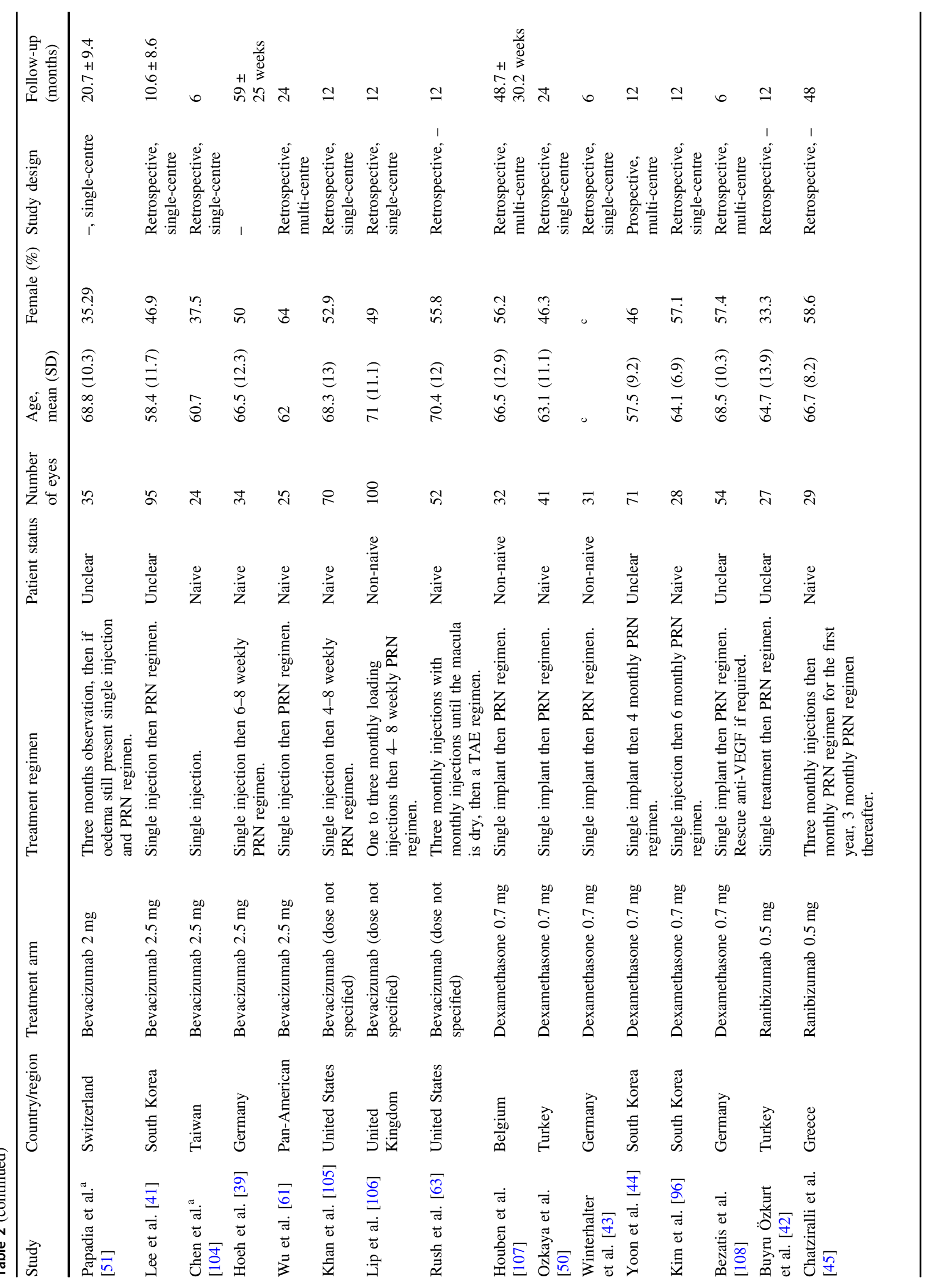




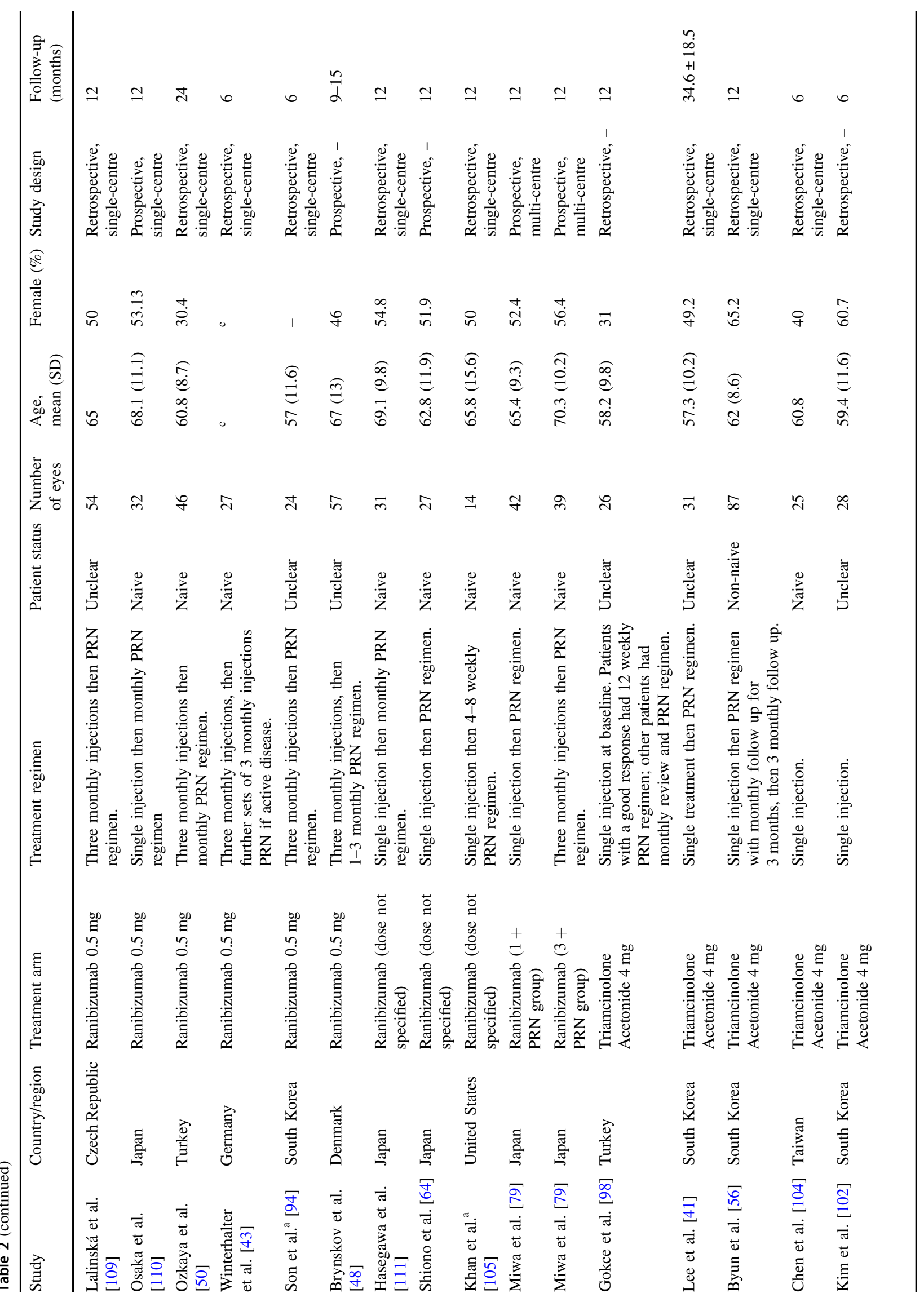




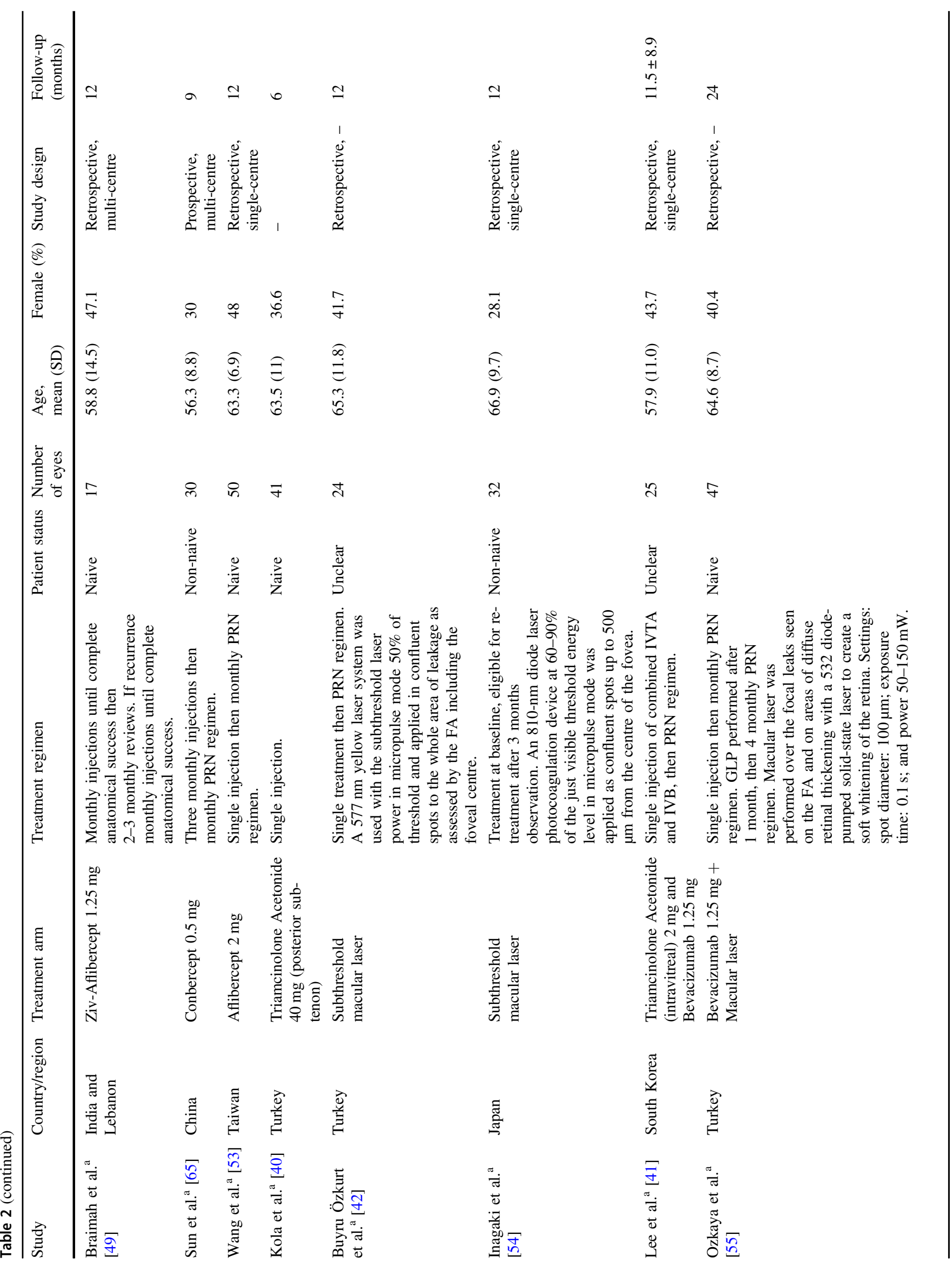




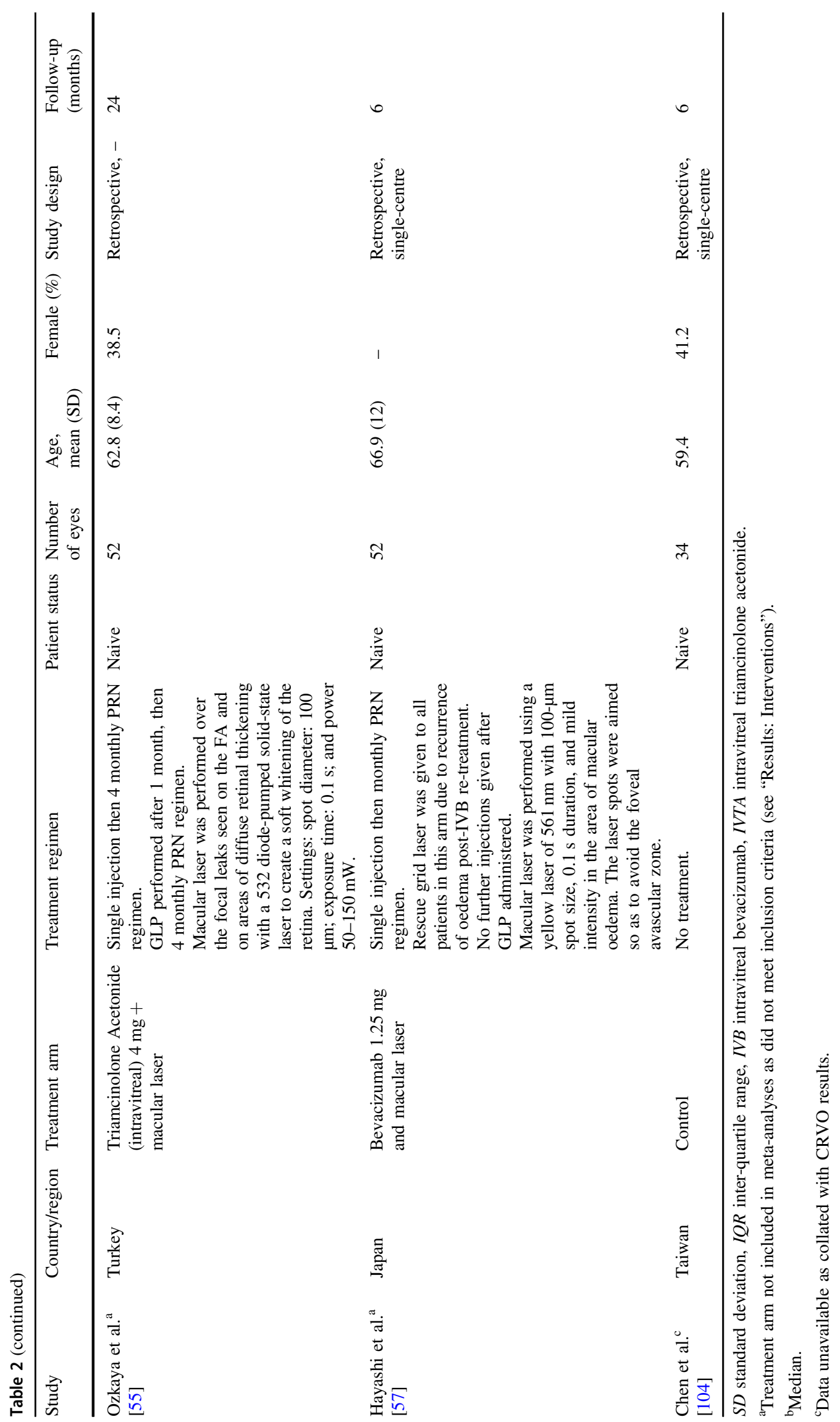


OCT technologies were used in the included studies, with time-domain OCTs used more frequently in older studies [38-41] and spectral-domain OCTs used frequently in more recent studies [42-45]. In some studies, different OCT technologies were used in different centres or over time $[41,46]$. Of the 48 studies, only 16 studies fully reported on competing interests and sources of support.

\section{Interventions}

Treatment arms with 25 or more eyes were included in meta-analyses. Ineligible treatment arms have been included in the summary tables if they belonged to a study with an eligible treatment arm. Using the criteria above, the meta-analyses were only applied to the following interventions:

- Intravitreal bevacizumab $1.25 \mathrm{mg}$

- Intravitreal bevacizumab $2.5 \mathrm{mg}$

- Intravitreal ranibizumab $0.5 \mathrm{mg}$

- Intravitreal dexamethasone implant $0.7 \mathrm{mg}$

- Intravitreal triamcinolone $4 \mathrm{mg}$

There were only single included real-world studies of the following interventions: bevacizumab $2 \mathrm{mg}$, aflibercept, grid laser, subthreshold laser, sub-tenon triamcinolone, conbercept, ziv-aflibercept and a variety of combination therapies.

\section{Baseline characteristics}

Weighted means and mean estimates as estimated by random-effects models or mixed-effects models for baseline characteristics of studies included in the meta-analysis are presented in Table 3. The mean (95\% CI) percentage of females across all studies estimated from the random-effects model was 52.7 (49.6, 55.8)\%; the mean age was 63.9 $(62.3,65.5)$ years. The mean baseline VA for the pooled data was $54.0(51.5,56.5)$ letters and the mean baseline CST was $501.3(483.5,519.1) \mu \mathrm{m}$.

The mixed-effects model estimates for mean $(95 \% \mathrm{CI})$ baseline VA for real-world studies in America, Asia and Europe, were 50.7 (41.2, 60.1), 54.5 (50.9, 58.2) and 53.8 (49.7, 58.0) letters. The mixed-effects model estimates for mean (95\% CI) baseline CST for studies from America, Asia and Europe were 450.5 (388.0, 513.1), 514.1 (488.6, $539.7)$ and $497.3(470.3,524.4) \mu \mathrm{m}$.

The mean baseline age for the various monotherapies was fairly similar, ranging from 62.1 to 65.8 years. The mean $(95 \% \mathrm{CI})$ baseline VA for bevacizumab $1.25 \mathrm{mg}$, bevacizumab $2.5 \mathrm{mg}$, dexamethasone, ranibizumab and triamcinolone was $52.0(49.4,54.6), 50.2(44.4,56.1), 53.6$ $(48.9,58.3), 61.6(57.7,65.5)$ and $49.4(45.2,53.6)$ letters.
Table 3 Weighted means and mean estimates as estimated by randomeffects models (for overall) or mixed-effects models (for by continent) for baseline characteristics of studies included in the meta-analysis.

\begin{tabular}{lclc}
\hline Variable & $\begin{array}{l}\text { Number of } \\
\text { eyes (studie } \\
\text { included) }\end{array}$ & $\begin{array}{l}\text { Weighted } \\
\text { mean }\end{array}$ & $\begin{array}{l}\text { Random or mixed- } \\
\text { effects estimate } \\
(95 \% \text { CI })\end{array}$ \\
\hline Females, \% & & & \\
Overall & $2378(39)$ & 52.5 & $52.7(49.6,55.8)$ \\
America & $185(3)$ & 54.1 & $54.2(43.6,64.9)$ \\
Asia & $1171(19)$ & 54.8 & $54.9(50.5,59.2)$ \\
Europe & $990(16)$ & 49.7 & $50.1(45.3,54.8)$ \\
Multicountry & $32(1)$ & 46.9 & - \\
Baseline age & & & $63.9(62.3,65.5)$ \\
Overall & $2267(40)$ & 63.9 & $67.4(62.0,72.9)$ \\
America & $185(3)$ & 67.4 & $62.8(60.7,64.9)$ \\
Asia & $1227(20)$ & 62.3 & $65.2(62.9,67.6)$ \\
Europe & $823(16)$ & 65.8 & - \\
Multicountry & $32(1)$ & 54.2 & $54.0(51.5,56.5)$ \\
Baseline VA & & & $50.7(41.2,60.1)$ \\
Overall & $2271(40)$ & 52.8 & $54.5(50.9,58.2)$ \\
America & $185(3)$ & 48.7 & $53.8(49.7,58.0)$ \\
Asia & $1227(20)$ & 53.5 & - \\
Europe & $827(16)$ & 52.8 & $501.3(483.5,519.1)$ \\
Multicountry & $32(1)$ & 54.5 & $450.5(388.0,513.1)$ \\
Baseline CST & & & $514.1(488.6,539.7)$ \\
Overall & $2199(40)$ & 503.8 & $497.3(470.3,524.4)$ \\
America & $185(3)$ & 446.8 & - \\
Asia & $1101(19)$ & 516.3 & 501.0 \\
Europe & $881(17)$ & 481.7 & \\
Multicountry & $32(1)$ & & \\
\hline Mixed effects & & \\
\hline
\end{tabular}

Mixed-effects estimates were not calculated if only a single study was available for that continent and are indicated by a dash.

The mixed-effects estimate $(95 \% \mathrm{CI})$ for baseline CST for bevacizumab $1.25 \mathrm{mg}$, bevacizumab $2.5 \mathrm{mg}$, dexamethasone, ranibizumab and triamcinolone was $491.9(469.6,514.2) \mu \mathrm{m}$, 507.1 (440.1, 574.1) $\mu \mathrm{m}, 523.5$ (489.3, 557.6) $\mu \mathrm{m}, 508.3$ $(474.9,541.7) \mu \mathrm{m}$ and $514.3(471.6,557.0) \mu \mathrm{m}$.

\section{Visual outcomes}

Weighted outcome means, outcome measures as estimated by random-effects models (for overall outcomes) or mixedeffects models (for treatment-group outcomes) and heterogeneity $\left(I^{2}\right)$ across studies are presented in Table 4.

The random-effects estimate for mean $(95 \% \mathrm{CI})$ change in VA was $12.4(10.4,14.5), 14.6(12.5,16.7)$ and 13.2 $(7.9,18.6)$ letters at 6 months $(n=1515), 12$ months $(n=$ $1727)$ and 24 months $(n=491)$, respectively.

At 6 months, mean $(95 \%$ CI) VA change for bevacizumab $1.25 \mathrm{mg}$, bevacizumab $2.5 \mathrm{mg}$, dexamethasone, ranibizumab and triamcinolone was 13.1 (10.2, 15.9), 14.4 $(6.8,22), 11.8(5.5,18.2), 12.8(8.4,17.1)$ and $8.8(3.3,14.3)$ letters, respectively. Except for dexamethasone which achieved a mean VA change of 10.9 (5.5, 16.2) letters, mean VA change continued to improve further at 12 months 
Table 4 Weighted outcome means, outcome measures as estimated by random-effects models (for overall outcomes) or mixed-effects models (for treatment-group outcomes), and heterogeneity $\left(I^{2}\right)$ across studies.

\begin{tabular}{|c|c|c|c|c|}
\hline Variable & $\begin{array}{l}\text { Number of eyes } \\
\text { (studies included) }\end{array}$ & Weighted mean & $\begin{array}{l}\text { Random or mixed-effects } \\
\text { estimate }(95 \% \mathrm{CI})\end{array}$ & $\overline{I^{2}(\%)}$ \\
\hline \multicolumn{5}{|l|}{ Females, \% } \\
\hline Overall & $2378(39)$ & 52.5 & $52.7(49.6,55.8)$ & \multirow[t]{6}{*}{48.0} \\
\hline Bevacizumab $1.25 \mathrm{mg}$ & $1404(23)$ & 54.2 & $54.8(50.9,58.8)$ & \\
\hline Bevacizumab $2.5 \mathrm{mg}$ & $167(3)$ & 47.6 & $48.0(37.3,58.6)$ & \\
\hline Dexamethasone & $226(5)$ & 51.6 & $52.9(44.1,61.8)$ & \\
\hline Ranibizumab & $384(9)$ & 48.2 & $47.6(40.8,54.4)$ & \\
\hline Triamcinolone & $197(5)$ & 54.3 & $53.1(44.3,62.0)$ & \\
\hline \multicolumn{5}{|l|}{ Baseline age } \\
\hline Overall & $2267(40)$ & 63.9 & $63.9(62.3,65.5)$ & \multirow[t]{6}{*}{91.2} \\
\hline Bevacizumab $1.25 \mathrm{mg}$ & $1293(24)$ & 64.2 & $63.4(61.6,65.3)$ & \\
\hline Bevacizumab $2.5 \mathrm{mg}$ & $167(3)$ & 61.5 & $64.3(60.7,67.8)$ & \\
\hline Dexamethasone & $226(5)$ & 63.2 & $65.8(62.9,68.6)$ & \\
\hline Ranibizumab & $384(9)$ & 65.9 & $65.0(62.1,68.0)$ & \\
\hline Triamcinolone & $197(5)$ & 60.2 & $62.1(59.2,65.0)$ & \\
\hline \multicolumn{5}{|l|}{ Baseline VA } \\
\hline Overall & $2271(40)$ & 52.8 & $54.0(51.5,56.5)$ & \multirow[t]{6}{*}{91.2} \\
\hline Bevacizumab $1.25 \mathrm{mg}$ & $1293(24)$ & 52.6 & $52.0(49.4,54.6)$ & \\
\hline Bevacizumab $2.5 \mathrm{mg}$ & $167(3)$ & 47.4 & $50.2(44.4,56.1)$ & \\
\hline Dexamethasone & $203(5)$ & 50.8 & $53.6(48.9,58.3)$ & \\
\hline Ranibizumab & $411(10)$ & 61.2 & $61.6(57.7,65.5)$ & \\
\hline Triamcinolone & $197(5)$ & 43.8 & $49.4(45.2,53.6)$ & \\
\hline \multicolumn{5}{|l|}{$\Delta$ VA 6 months } \\
\hline Overall & $1515(26)$ & 13.0 & $12.4(10.4,14.5)$ & \multirow[t]{6}{*}{68.2} \\
\hline Bevacizumab $1.25 \mathrm{mg}$ & $752(14)$ & 13.6 & $13.1(10.2,15.9)$ & \\
\hline Bevacizumab $2.5 \mathrm{mg}$ & $133(2)$ & 17.4 & $14.4(6.8,22.0)$ & \\
\hline Dexamethasone & $134(3)$ & 12.0 & $11.8(5.5,18.2)$ & \\
\hline Ranibizumab & $299(8)$ & 10.7 & $12.8(8.4,17.1)$ & \\
\hline Triamcinolone & $197(5)$ & 12.2 & $8.8(3.3,14.3)$ & \\
\hline \multicolumn{5}{|l|}{$\Delta$ VA 1 year } \\
\hline Overall & $1727(29)$ & 14.1 & $14.6(12.5,16.7)$ & \multirow[t]{6}{*}{77.5} \\
\hline Bevacizumab $1.25 \mathrm{mg}$ & $1049(20)$ & 14.5 & $15.5(13.4,17.6)$ & \\
\hline Bevacizumab $2.5 \mathrm{mg}$ & $133(2)$ & 20.8 & $18.3(11.1,25.5)$ & \\
\hline Dexamethasone & $128(3)$ & 9.1 & $10.9(5.5,16.2)$ & \\
\hline Ranibizumab & $273(7)$ & 11.8 & $15.9(11.3,20.5)$ & \\
\hline Triamcinolone & $144(3)$ & 14.1 & $10.8(4.5,17.1)$ & \\
\hline \multicolumn{5}{|l|}{$\Delta \mathrm{VA} 2$ years } \\
\hline Overall & $491(7)$ & 14.0 & $13.2(7.9,18.6)$ & \multirow[t]{6}{*}{64.2} \\
\hline Bevacizumab $1.25 \mathrm{mg}$ & $211(4)$ & 13.4 & $10.9(-29.6,51.4)$ & \\
\hline Bevacizumab $2.5 \mathrm{mg}$ & $133(2)$ & 20.0 & $16.1(-39.1,71.3)$ & \\
\hline Dexamethasone & $41(1)$ & 3.0 & - & \\
\hline Ranibizumab & $75(2)$ & 9.9 & $12.4(-39.0,63.8)$ & \\
\hline Triamcinolone & $31(1)$ & 17.5 & - & \\
\hline \multicolumn{5}{|l|}{ Baseline CST } \\
\hline Overall & $2199(40)$ & 503.8 & $501.3(483.5,519.1)$ & \multirow[t]{2}{*}{86.3} \\
\hline Bevacizumab $1.25 \mathrm{mg}$ & $1293(24)$ & 497.9 & $491.9(469.6,514.2)$ & \\
\hline
\end{tabular}


Table 4 (continued)

\begin{tabular}{|c|c|c|c|c|}
\hline Variable & $\begin{array}{l}\text { Number of eyes } \\
\text { (studies included) }\end{array}$ & Weighted mean & $\begin{array}{l}\text { Random or mixed-effects } \\
\text { estimate }(95 \% \mathrm{CI})\end{array}$ & $\overline{I^{2}(\%)}$ \\
\hline Bevacizumab $2.5 \mathrm{mg}$ & $72(2)$ & 518.6 & $507.1(440.1,574.1)$ & \\
\hline Dexamethasone & $257(6)$ & 500.1 & $523.5(489.3,557.6)$ & \\
\hline Ranibizumab & $411(10)$ & 528.6 & $508.3(474.9,541.7)$ & \\
\hline Triamcinolone & $166(4)$ & 488.5 & $514.3(471.6,557.0)$ & \\
\hline Overall & $1294(25)$ & -167.2 & $-159.2(-203.8,-114.6)$ & 93.9 \\
\hline Bevacizumab $1.25 \mathrm{mg}$ & $662(13)$ & -185.4 & $-186.2(-240.0,-132.5)$ & \\
\hline Bevacizumab $2.5 \mathrm{mg}$ & $38(1)$ & -198.0 & - & \\
\hline Dexamethasone & $216(5)$ & -154.8 & $-101.8(-162.5,-41.1)$ & \\
\hline Ranibizumab & $299(8)$ & -141.9 & $-161.0(-242.6,-79.5)$ & \\
\hline Triamcinolone & $79(3)$ & -129.0 & $-159.4(-249.6,-69.2)$ & \\
\hline \multicolumn{5}{|l|}{$\Delta \mathrm{CST} 1$ year } \\
\hline Overall & $1325(24)$ & -190.8 & $-181.7(-230.7,-132.7)$ & 96.1 \\
\hline Bevacizumab $1.25 \mathrm{mg}$ & 829 (17) & -206.6 & $-198.2(-250.6,-145.9)$ & \\
\hline Bevacizumab $2.5 \mathrm{mg}$ & $38(1)$ & -194.0 & - & \\
\hline Dexamethasone & $128(3)$ & -184.3 & $-143.1(-213.2,-73.0)$ & \\
\hline Ranibizumab & $242(6)$ & -128.8 & $-189.8(-296.9,-82.6)$ & \\
\hline Triamcinolone & $88(2)$ & -221.3 & $-189.2(-266.9,-111.6)$ & \\
\hline \multicolumn{5}{|l|}{$\Delta \mathrm{CST} 2$ years } \\
\hline Overall & $303(5)$ & -236.3 & $-209.3(-328.1,-90.6)$ & 93.6 \\
\hline Bevacizumab $1.25 \mathrm{mg}$ & $149(3)$ & -262.9 & $-213.2(-501.9,75.5)$ & \\
\hline Bevacizumab $2.5 \mathrm{mg}$ & $38(1)$ & -210.0 & - & \\
\hline Dexamethasone & $41(1)$ & -256.0 & - & \\
\hline Ranibizumab & $75(2)$ & -186.0 & $-184.0(-539.3,171.3)$ & \\
\hline Triamcinolone & - & - & - & \\
\hline \multicolumn{5}{|l|}{ Injections 6 months } \\
\hline Overall & $692(10)$ & 2.5 & $2.7(1.9,3.4)$ & 98.1 \\
\hline Bevacizumab $1.25 \mathrm{mg}$ & $579(7)$ & 2.6 & $2.9(2.1,3.6)$ & \\
\hline Bevacizumab $2.5 \mathrm{mg}$ & - & - & - & \\
\hline Dexamethasone & $31(1)$ & 1.1 & - & \\
\hline Ranibizumab & $54(2)$ & 3.3 & $3.3(2.1,4.5)$ & \\
\hline Triamcinolone & $28(1)$ & 1.0 & - & \\
\hline \multicolumn{5}{|l|}{ Injections 12 months } \\
\hline Overall & $1337(24)$ & 3.5 & $3.6(2.9,4.2)$ & 99.6 \\
\hline Bevacizumab $1.25 \mathrm{mg}$ & $882(17)$ & 3.7 & $3.4(2.8,4.0)$ & \\
\hline Bevacizumab $2.5 \mathrm{mg}$ & - & - & - & \\
\hline Dexamethasone & $69(2)$ & 1.8 & $2.1(1.4,2.8)$ & \\
\hline Ranibizumab & $273(7)$ & 4.2 & $4.9(4.2,5.6)$ & \\
\hline Triamcinolone & $113(2)$ & 1.2 & $2.0(1.3,2.7)$ & \\
\hline \multicolumn{5}{|l|}{ Injections 24 months } \\
\hline Overall & $365(6)$ & 5.0 & $5.2(2.1,8.3)$ & 98.2 \\
\hline Bevacizumab $1.25 \mathrm{mg}$ & $211(4)$ & 5.3 & $5.7(0.0,15.3)$ & \\
\hline Bevacizumab $2.5 \mathrm{mg}$ & $38(1)$ & 4.3 & - & \\
\hline Dexamethasone & $41(1)$ & 2.7 & - & \\
\hline Ranibizumab & $75(2)$ & 5.7 & $5.6(0.0,21.9)$ & \\
\hline Triamcinolone & - & - & - & \\
\hline
\end{tabular}

Dashes indicate no studies (or only 1 for random- and mixed-effects estimates) were available for that treatment group. Moderators for mixedeffects estimates analysing outcomes by treatment group included age, VA and CST measured at baseline. 
to $15.5(13.4,17.6), 18.3(11.1,25.5), 15.9(11.3,20.5)$ and $10.8(4.5,17.1)$ letters for bevacizumab $1.25 \mathrm{mg}$, bevacizumab $2.5 \mathrm{mg}$, ranibizumab and triamcinolone, respectively. At 24 months, mean VA change then declined slightly to 10.9 (-29.6, 51.4), 16.1 (-39.1, 71.3), 12.4 $(-39.0,63.8)$ letters for bevacizumab $1.25 \mathrm{mg}$, bevacizumab $2.5 \mathrm{mg}$ and ranibizumab, respectively. No mixedeffects estimates were available for dexamethasone and triamcinolone at 24 months as only one study was available for each of the treatments.

\section{Anatomical outcomes}

The random-effects estimate for mean $(95 \% \mathrm{CI})$ change in CST was $-159.2(-203.8,-114.6) \mu \mathrm{m},-181.7(-230.7$, $-132.7) \mu \mathrm{m}$ and $-209.3(-328.1,-90.6) \mu \mathrm{m}$ at 6 months $(n=1294), 12$ months $(n=1325)$ and 24 months $(n=$ 303), respectively.

Mean (95\% CI) CST change for bevacizumab $1.25 \mathrm{mg}$ at 6 months was $-186.2(-240.0,-132.5) \mu \mathrm{m},-198.2$ $(-250.6,-145.9) \mu \mathrm{m}$ at 12 months, and $-213.2(-501.9$, $75.5) \mu \mathrm{m}$ at 24 months. Mean (95\% CI) CST change for ranibizumab initially reduced at 6 and 12 months, by $-161.0(-242.6,-79.5) \mu \mathrm{m}$ and $-189.8(-296.9,-82.6)$ $\mu \mathrm{m}$, respectively, with the change declining to -184.0 $(-539.3,171.3) \mu \mathrm{m}$ at 24 months.

For dexamethasone, mean (95\% CI) CST change was $-101.8(-162.5,-41.1) \mu \mathrm{m}$ and $-143.1(-213.2,-73.0)$ $\mu \mathrm{m}$ at 6 and 12 months, respectively. For triamcinolone, mean (95\% CI) CST change was $-159.4(-249.6,-69.2)$ $\mu \mathrm{m}$ and $-189.2(-266.9,-111.6) \mu \mathrm{m}$ at 6 and 12 months, respectively. No mixed-effects estimates were available for bevacizumab $2.5 \mathrm{mg}$ at all time points and for dexamethasone and triamcinolone at 24 months.

\section{Presence of SRF at baseline}

The presence of SRF at baseline was only reported in 5 of the 48 studies $(10 \%)$, with its presence in eyes ranging between 4.3 and $81 \%$ within treatment arms. Visual outcomes were reported according to the presence of SRF at baseline in two studies. In one study, they identified final visual acuity was not significantly different in the $81 \%$ of eyes with SRF at baseline compared with the whole cohort, however baseline VA for both groups was not specified [47]. In the other study, similarly, it was reported that there was no statistically significant difference in the change of visual acuity at 12 months between the groups with and without SRF [48].

\section{Treatment burden}

Patients received a mean $(95 \%$ CI) estimate of $2.7(1.9,3.4)$, $3.6(2.9,4.2)$ and $5.2(2.1,8.3)$ injections at 6 months $(n=692), 12$ months $(n=1337)$ and 24 months $(n=365)$, respectively, across all treatment groups.

For patients who received steroid therapies, there were generally a lower number of injections or implants compared with anti-VEGF therapies. Patients on steroid therapies received a mean $(95 \%)$ estimate of $2.1(1.4,2.8)$ dexamethasone implants and $2.0(1.3,2.7)$ intravitreal triamcinolone injections over 12 months. In contrast, patients in the intravitreal bevacizumab $1.25 \mathrm{mg}$ and intravitreal ranibizumab treatment groups received a mean estimate of $3.4(2.8,4.0)$ and $4.9(4.2,5.6)$ injections over 12 months, respectively.

Mean number of laser applications was reported by two of the three treatment arms investigating subthreshold micropulse laser photocoagulation and two of the three treatment arms investigating combination therapies that involved macular laser.

Mean number of visits were reported in only $4(6 \%)$ of the 71 treatment arms reported $[49,50]$.

\section{Heterogeneity}

The amount of heterogeneity $\left(I^{2}\right)$ for change in VA ranged from 64.1 to $78.2 \%$, indicating moderate heterogeneity across studies. Heterogeneity for change in CST and injection frequency was consistently $>75 \%$, indicating substantial heterogeneity across studies for these outcome measures.

Of the 48 studies, 28 were single-arm studies and 20 assessed multiple treatment arms. The study was conducted prospectively in 12 treatment arms, retrospectively in 56 treatment arms and study design was not clear in 3 treatment arms. There were 71 treatment arms, 66 of which were monotherapies, 1 was a control arm and 4 were combination arms.

Intravitreal anti-VEGF therapies were the most widely investigated, being studied in $77 \%$ of treatment arms. AntiVEGF treatment arms were dominated by bevacizumab (36 arms) and ranibizumab (13 arms). Initiation of therapy varied, however the vast majority of studies adopted subsequent Pro re nata (PRN) treatment regimes. The dose of bevacizumab was typically $1.25 \mathrm{mg}$ ( $28 \mathrm{arms}$ ), but in some studies a dose of $2.5 \mathrm{mg}$ was used (4 arms), one study used $2 \mathrm{mg}$ and 3 arms did not specify the dose [51]. When reported, the dose of ranibizumab was consistently $0.5 \mathrm{mg}$.

For intravitreal bevacizumab, 21 arms (58\%) used a single injection followed by a PRN regimen, 7 arms (19\%) used 3 loading injections followed by a PRN regimen, 2 arms (6\%) used single or 3 loading injections followed by a PRN regimen, 2 arms (6\%) used single injection only, while another 4 arms (11\%) utilised had different and unique treatment regimens $[47,49,51,52]$. There were six intravitreal ranibizumab arms (46\%) that used a single injection 
followed by a PRN regimen and seven arms (54\%) used three loading injections followed by a PRN regimen.

Only one treatment arm was included in our review using intravitreal aflibercept administered as a single $2.0 \mathrm{mg}$ injection followed by monthly PRN treatment [53]. Another treatment arm used conbercept with a loading phase of three injections at one month intervals followed by a PRN regimen. Ziv-aflibercept was used in a treatment arm with injections given monthly until the macula was free of all intraretinal and SRF and/or the CMT $\leq 250 \mu \mathrm{m}$ [49].

The next most reported intervention was corticosteroid therapy representing $20 \%$ of treatment arms (intravitreal dexamethasone $43 \%$, intravitreal triamcinolone $50 \%$, subtenon triamcinolone 7\%). For intravitreal dexamethasone and triamcinolone, single therapies were administered at baseline and decisions for re-treatment were on a PRN basis.

Subthreshold laser photocoagulation was investigated in two treatment arms with clearly defined energy parameters delivered at baseline then on a PRN basis $[42,54]$. One study used a $810 \mathrm{~nm}$ diode laser photocoagulation device and avoided the foveal centre, while the other used a 577 $\mathrm{nm}$ yellow laser system to treat the entire area of leakage demonstrated on fluorescein angiography including the foveal centre [42].

Combination therapy was investigated in three treatment arms that utilised macular grid laser in combination with intravitreal bevacizumab [55] or intravitreal triamcinolone [55]. Another study used the combination of intravitreal triamcinolone and bevacizumab given at baseline then on a PRN basis [41].

\section{Safety outcomes}

The safety outcomes of each study are available as an online supplement (Supplementary Table G).

\section{Qualitative description of ocular and systemic safety outcomes reported}

In some studies, the adverse events for BRVO eyes could not be differentiated from CRVO eyes and therefore we have not included them in the following description. Of the 71 treatment arms, ocular adverse events were discussed in 56 (79\%) treatment arms. However, few studies specified commented on the specific breakdown of complications. Of these studies, 29 studies reported zero ocular adverse events.

Only $35(51 \%), 27(38 \%)$ and $15(21 \%)$ of treatment arms specifically reported zero rates of endophthalmitis (excluding treatment arms investigating subthreshold laser photocoagulation), retinal detachment or rubeotic glaucoma, respectively.

The occurrence of neovascularisation was not well reported. Less than $20 \%$ of treatment arms commented on this complication. There were no reported cases of NVD and there were $27 \mathrm{NVE}$ events and $1 \mathrm{NVI} / \mathrm{A}$ event.

Increased IOP requiring IOP-lowering medications was reported in $30(42 \%)$ of the included treatment arms. It was reported in 10 of 14 steroid treatment arms and 20 of the 57 non-steroid treatment arms. Of the 10 steroid treatment arms where this was reported, 7 required IOP-lowering medications compared with 5 of the 20 non-steroid treatment arms.

Macular changes affecting vision was rarely reported as a category of ocular complication, with only two (3\%) of the included treatment arms commenting on this. These studies focused on epiretinal membrane formation. One of these treatment arms utilised intravitreal bevacizumab and the other utilised intravitreal triamcinolone, both in combination with macular grid laser.

Of the 71 treatment arms, $18(25 \%)$ arms specifically reported rates of vitreous haemorrhage, with 3 treatment arms (all assessing intravitreal bevacizumab $1.25 \mathrm{mg}$ ) reporting 1 event each.

\section{Cataract}

There were variations as to how cataract outcomes were reported. Overall, $31(44 \%)$ of the 71 treatment arms reported on any of the following cataract outcomes: cataract progression, traumatic cataract and/or patients requiring cataract surgery. Another five (7\%) treatment arms excluded patients who required cataract surgery from the study and did not report on other cataract outcomes, however two (3\%) treatment arms excluded those who required cataract surgery from the study but did reported on other cataract outcomes [56]. Only 16 treatment arms reported baseline lens status but did not analyse outcomes according to this characteristic.

\section{Need for retinal laser therapy for neovascularisation}

In 14 treatment arms, sectoral laser photocoagulation was administered for non-perfused or ischaemic areas, or if there was ocular neovascularisation. The type and settings used were only described by one study [57] while another only specified the type of laser [58].

\section{Rescue therapy}

Only in $23(32 \%)$ of the 71 treatment arms, it was specified whether patients received rescue macular laser therapy in addition to the main therapy being investigated.

In 12 of these treatment arms, grid laser photocoagulation was administered during the study if there was suboptimal response to the main therapy investigated; however, the settings of the laser photocoagulation treatment were only described by two studies $[49,57]$. The criteria for 
judging suboptimal response were not always defined [41]. In a study which identified no significant difference in visual outcomes between ziv-aflibercept and bevacizumab for macular oedema secondary to BRVO, it should be noted that $41 \%$ of bevacizumab treated eyes had additional macular laser whereas no eyes in the ziv-aflibercept group were reported to have received additional macular laser treatment [49].

\section{Macular ischaemia}

The absence or presence of macular ischaemia was reported in 17 of 71 treatment arms (24\%) and of these arms, macular ischaemia was present in 14 treatment arms (20\%), as shown in online supplement (Supplementary Table H). There were three treatment arms that reported no macular ischaemia at baseline, confirmed with fluorescein angiography. In 12 treatment arms (17\%), presence of macular ischaemia was specified as an exclusion criterion. In two treatment arms, it was uncertain as to whether the ischaemic areas were at the macula or in the periphery $[38,59,60]$.

\section{Peripheral ischaemia}

Peripheral ischaemia was reported in 23 of 71 treatment arms (32\%). In five (7\%) of the studies eyes were excluded if the ischaemic areas were larger than a set area.

\section{Time to commencement of treatment}

There was different terminology and a wide range of approaches in describing time to commencement of treatment, as shown in the online supplement (Supplementary Table H). A number of studies specified this duration to be from time of 'symptom onset' or 'from diagnosis', while some reported 'duration of macular oedema' or 'duration of disease'.

\section{Treatment-naïve at baseline}

At baseline, there were 38 treatment-naïve arms, 12 nonnaïve treatment arms and 21 treatment arms where this information was not clearly provided.

\section{Risk factors}

\section{Hypertension}

The proportion of patients who were hypertensive was reported in 36 treatment arms (51\%), and in 6 of these treatment arms, 'uncontrolled hypertension' was excluded. A further eight (11\%) treatment arms excluded patients with 'uncontrolled hypertension' but did not report the proportion of patients who had hypertension. There was a significant variation in rates of hypertension in the population studied ranging from 27.3 to $100 \%$ in the treatment arms. Two treatment arms from a single study reported 'patients with a history of uncontrolled hypertension....were not usually injected with bevacizumab, but this decision was left at the discretion of the treating physician' [61].

\section{Diabetes mellitus}

The proportion of patients who had diabetes mellitus was reported in 32 treatment arms (45\%). There was a significant variation in rates of diabetes mellitus in the population studied ranging from 4 to $55.6 \%$ in treatment arms. Two studies excluded patients with diabetes mellitus and two studies excluded patients with 'uncontrolled diabetes' [62, 63].

\section{Smoking status}

Only one study [45] reported percentage of smokers (55\%) but did not report how this impacted on visual outcomes.

\section{History of strokes and myocardial infarction}

There was a range of terminology used when describing strokes and myocardial infarction, ranging from 'thromboembolic events', 'cardiovascular disease' and 'systemic thrombosis'. It was not always clear whether this related to a previous stroke or myocardial infarction. There were 6 treatment arms that reported on the proportion of patients with a history of these diseases, 2 treatment arms reported zero patients with such risk factors and 15 treatment arms excluded patients with such diseases.

Two treatment arms from a single study reported 'patients with a history of...recent thrombo-embolic events were not usually injected with bevacizumab, but this decision was left at the discretion of the treating physician' [61].

\section{Systemic adverse events}

Systemic adverse events were only reported by 30 (42\%) of the 71 treatment arms, of which 27 arms reported no systemic adverse events. The remaining three treatment arms reported a total of four systemic adverse events [46, 64, 65]. There was an episode of palpitations, an episode of chest pain, a non-ocular serious adverse event and a death $[46,64,65]$.

\section{Discussion}

Real-world studies confirm that treatment can lead to visual gains and anatomical resolution of macular oedema 
secondary to BRVO. Where meta-analysis of anti-VEGF agents was possible, the VA gains and CST improvements were less impressive in the real-world than in RCTs. This might relate to reduced injection numbers (on average $<6$ intravitreal anti-VEGF injections over 24 months) and different baseline characteristics in the real world compared with RCTs.

These results may reflect the challenge of delivering frequent anti-VEGF therapy in the real-world setting where patients have other co-morbidities and healthcare resources are stretched. An unmet need appears to be longer-acting therapies, which would increase the chances of RCT results being replicated in normal clinical practice. It would also be helpful to report the number of visits patients attend in real-world settings to more accurately determine treatment burden.

Where meta-analyses were possible for intravitreal steroid therapy, VA gains were more comparable between the real-world and RCT populations. This could be due to the small number of included studies or the more manageable number of treatments required.

In study populations receiving ranibizumab $0.5 \mathrm{mg}$ in the BRAVO and the BRIGHTER study, the mean age at baseline was 67.5 (SD 11.8) and 64.7 (SD 10.3) years, respectively, similar to the included real-world studies $[8,12]$. Mean $(95 \% \mathrm{CI})$ baseline VA was better in the study populations of included real-world studies at 61.6 (57.7, 65.5) letters compared with RCTs, with baseline VA 53 (SD 12.5) letters in groups receiving ranibizumab $0.5 \mathrm{mg}$ in BRAVO and 59.5 (SD 11.8) letters in BRIGHTER [8, 12]. Mean $(95 \% \mathrm{CI})$ baseline CST in our included real-world studies was thinner at $508.3(474.9,541.7) \mu \mathrm{m}$ compared with the baseline central subfield foveal thickness in BRIGHTER at 529.5 (SD 145) $\mu \mathrm{m}$ [12] and the baseline CFT in BRAVO at 551.7 (SD 223.5) $\mu \mathrm{m}$ [8].

As for the studies assessing bevacizumab $1.25 \mathrm{mg}$, the included real-world studies had a mean $(95 \% \mathrm{CI})$ age of 63 (61.6, 65.3) years. This is older compared with the study population of MARVEL receiving $1.25 \mathrm{mg}$ bevacizumab, with a mean of 50.5 (SD 8.7) years [16]. Mean (95\% CI) baseline VA was $52.0(49.4,54.6)$ letters in the included real-world studies, better than that of MARVEL's at 56.1 (SD 10) letters [16]. Mean (95\% CI) baseline CST in our included studies was $491.9(469.6,514.2) \mu \mathrm{m}$, which was similar to the mean CRT of 491.6 (SD 155.1) $\mu \mathrm{m}$ in the MARVEL study [16].

For the triamcinolone studies, our real-world study sample's mean $(95 \% \mathrm{CI})$ age was $62.1(59.2,65)$ years. This population is younger compared with that of SCORE, where mean age was 67.2 (SD 11.5) and 68.1 (SD 10.6) years for the groups, which received intravitreal triamcinolone 1 and $4 \mathrm{mg}$, respectively [4]. Mean $(95 \% \mathrm{CI}) \mathrm{VA}$ at baseline in included real-world studies was worse than that of SCORE at $49.4(45.2,53.6)$ letters compared with 58.2 (SD 11.3) and 56.1 (SD 13.4) letters for the treatment arms that received triamcinolone 1 and $4 \mathrm{mg}$, respectively [4]. Centre point thickness at baseline however, was thicker in the SCORE study at 521 (SD 198) $\mu \mathrm{m}$ and 516 (SD 160) $\mu \mathrm{m}$ for patients receiving triamcinolone 1 and $4 \mathrm{mg}$, respectively [4]. However, note that the OCT outcomes measured in real-world studies and RCTs vary, which include CST, CFT and CSFT, therefore these OCT measures may not be directly comparable. As the outcome data reported in the GENEVA study could not be differentiated into BRVO and CRVO eyes, it could not be compared with the dexamethasone implant data from our included real-world studies.

In RCTs such as VIBRANT [13] and BRAVO, increasing time to commencement of treatment was a negative predictor of outcome. In this review it has been observed that real-world studies lacked consistency in the use of terminology and approaches in describing time to commencement of treatment.

Baseline age on average appeared to be slightly lower in Asian populations (62.8 years) compared with the American (67.4 years) and European populations (65.2 years) studied. Baseline VA and CST were lower in the American studies compared with other real-world studies. The presence of SRF and its association with visual outcomes was only reported in two included studies [47, 48]. However, some studies have suggested that serous retinal detachment was a negative predictor of visual prognosis in BRVO patients $[66,67]$, while subgroup analysis of BRAVO data reported that presence of central SRF did not influence visual outcomes [68]. Therefore, capturing such anatomical features and exploring their associations with outcomes in realworld studies may help us understand possible prognostic factors for macular oedema secondary to BRVO.

Included studies utilised a variety of time-domain and spectral-domain OCTs. There may be limitations to the comparability of outcomes of these studies because of the potential differences between OCT technologies in fluid detection and thickness measurements $[69,70]$.

The recording of treatment-naïve status at baseline is an important parameter that was not consistently recorded. In RCTs, study populations were mostly treatment-naïve or have a period without treatment prior to commencing intervention. Switching studies were excluded from this analysis.

Another baseline characteristic that was poorly reported in the included real-world studies was the presence of ischaemia. Many studies did not report on this characteristic and of those studies that did, some did not clearly specify that whether the location of ischaemia was macular or peripheral. Gains in vision were comparable in subgroups with and without macular ischaemia at baseline in the 
BRIGHTER RCT [12]. One included real-world study [71] reported that no significant difference in visual and anatomical outcomes was found between those with and without macular ischaemia [71], whilst another study suggested macular ischaemia was a negative predictor for visual outcomes [45].

There are many monotherapy and combination therapy options for the management of macular oedema secondary to BRVO. This is reflected in the wide range of treatment interventions and dosing regimens reported in real-world studies. There were limited real-world studies on some of the more recently available intravitreal anti-VEGF therapies.

There was zero occurrence of endophthalmitis, retinal detachment, rubeotic glaucoma or NVD reported in included treatment arms. An explanation is that these adverse events are very uncommon, but it is also possible that there is under-reporting of safety outcomes in realworld studies compared with RCTs. Endophthalmitis is a potentially devastating complication that can occur after intravitreal injections, and a meta-analysis of clinical trials and real-world data on infectious endophthalmitis after intravitreal anti-VEGF injections for any indication identified 197 cases of endophthalmitis among a total of 350,535 intravitreal anti-VEGF injections, $0.056 \%(95 \%$ CI, 0.049-0.065\%) [72].

The use of sectoral laser photocoagulation was described in some of the included studies, but the indication for which it was used in the real world was variable. In some studies, it was applied when significant peripheral ischaemia is detected while in others, this is only done when there is development of active neovascularisation or vitreous haemorrhage. RCTs have either specified that patients can receive scatter photocoagulation if there is ocular neovascularisation [14] or have excluded those anticipated to require scatter laser photocoagulation within 4 months of starting treatment [8]. The Royal College of Ophthalmologists (RCOphth) guidelines state 'it is recommended that sector laser photocoagulation is applied once retinal or optic disc neovascularisation occur' [7]. Reporting of use of sectoral laser photocoagulation and when it is specifically used in patients in real-world studies may help answer questions as to the optimum timing.

Notably, less than half of the included treatment arms reported systemic safety outcomes. Understandably, ophthalmologists may not always have this data and systemic adverse events may not have been recorded for therapies such as local laser but it would be useful to know the background rate of systemic adverse events in these populations. There is a controversy whether intravitreal antiVEGF treatment causes similar problems to systemically delivered anti-VEGF of increased blood pressure and risk of thrombo-embolic events. Results of meta-analyses of systemic cardiovascular complications in patients receiving intravitreal anti-VEGF therapies are conflicting [73-75]. RCTs excluded patients with recent myocardial infarction, cerebrovascular events and uncontrolled hypertension [8, 12, 17, 19]. Real-world studies therefore, offer an opportunity to observe outcomes of therapies for these potentially high-risk groups. There is also the potential to link registries of RVO therapy and thrombo-embolic events to identify any association.

Risk factors for BRVO have been documented in epidemiological studies, and these include cardiovascular risk factors such as hypertension, diabetes mellitus and smoking [76]. A case-control study identified that BRVO was associated with an increased risk of subsequently developing hypertension, diabetes, congestive heart failure and cerebrovascular disease [77] and the RCOphth guidelines recommend careful cardiovascular assessment and treatment of cardiovascular risk factors in patients with RVO [7]. Although these risk factors were recorded in some of the included treatment arms, at times the terminology used to describe them was unclear as to what they constituted e.g., 'cardiovascular disease'. In view of the importance of these risk factors in BRVO, we suggest that they should be reported in a standardised manner.

Rescue therapies with macular laser and anti-VEGF were not consistently described in the included real-world studies. It has been observed that only a small number of studies reported the type of laser and settings used in laser photocoagulation therapy. Macular laser photocoagulation can potentially affect outcomes as shown in the BVOS study [2] and there can be a widely varying settings and laser type used in real-world studies $[49,57]$. As use of any rescue therapy can potentially impact outcomes, it is important that it is fully described in real-world studies.

It has also been observed that a number of studies included hemi-retinal vein occlusions (HRVO) together with BRVO eyes in treatment arms $[48,78,79]$. There does not appear to be a consensus whether HRVO is a variant of BRVO or CRVO or is a separate condition, with some reports of differences in risk factors, clinical features and systemic associations between the three groups [80]. However, in the SCORE study there was no significant difference in the three disease entities in frequency of treatments and adverse events [81]. Reporting outcomes for the HRVO subgroups in future real-world studies may provide more information to differentiate it from the other disease entities.

Notably, none of the included studies in this review reported on quality of life outcomes, despite the known detrimental impact of RVOs in vision-related quality of life [82]. Results from the BRAVO trial indicated that patients with macular oedema secondary to BRVO treated with monthly ranibizumab had greater improvements in visionrelated function compared with sham-treated patients 
through 6 months [8]. We propose that it would be beneficial for prospective real-world studies to record quality of life outcomes to allow payers of healthcare services to understand the broader benefits of treatment.

The included real-world studies in this systematic review were generally of lower quality. Because of the lack of a control group, a case series is prone to bias, occupies a low position in the hierarchy of evidence and is considered the weakest study design from which to obtain evidence on effectiveness [83]. Although some included studies in this review had a comparator group, characteristics and outcomes were analysed by treatment arms and therefore we treated every treatment arm as a case series. The quality appraisal of case series studies checklist published by IHE $[31,84]$ was chosen mainly because it is one of the preferred tool recommended in the manual for developing NICE guidelines [30].

The strengths of this meta-analysis are its thorough literature search, large sample size with over 2530 eyes and extraction of data and quality assessment of the original studies independently by two authors. However, there are several limitations to this review. First, varied follow-up periods, treatment regimens and study populations led to considerable heterogeneity, which limits the interpretability of the pooled results. The meta-analyses were analysed by treatment and dose. We could not perform sub-analyses by treatment regimen as there was too much variability between included studies. Although the average visual and anatomical outcomes were recorded in the majority of the included studies, the spread of data was not consistently reported. There was non-standardised and incomplete capture and reporting of baseline characteristics, risk factors, treatment burden, use of rescue therapies, quality of life data and ocular and systemic adverse events.

A consensus statement on the minimum dataset for collection of real-world outcomes related to RVOs is required so future real-world studies can more easily be compared. A minimum set of standardised patient-centred outcome measures for macular degeneration was facilitated by the International Consortium for Health Outcomes Measurement to allow easy comparison between different units nationally and internationally [85]. The Fight Retinal Blindness! registry has been tracking outcomes of therapy for neovascular age-related macular degeneration and diabetic macular oedema with a mandatory minimum dataset [86]. A standardised web-based tool has been developed to prospectively collect a minimum mandatory dataset for outcomes of therapy for macular oedema secondary to retinal vein occlusions $[87,88]$. The American Academy of Ophthalmology Intelligent Research in Sight (IRIS) registry launched in 2014 has already become the largest American clinical specialty data registry [89]. The
IRIS registry is designed to extract data from the practice's server, which contains the electronic medical record (EMR) database using systems integrator software. A limitation of the IRIS registry approach is that a minimum dataset is not mandated [89].

In conclusion, although visual and anatomical gains can be seen in the real-world management of macular oedema secondary to BRVO, these gains particularly for anti-VEGF therapy were not as impressive as the seminal RCTs. This might be explained by differences in baseline characteristics and reduced injection frequency in the real world. To improve the quality of real-world studies in this field and to strengthen the evidence base, there is an urgent need for a consensus on the minimum dataset of efficacy, treatment burden and safety data on therapies for macular oedema secondary to BRVO.

\section{Compliance with ethical standards}

Conflict of interest DB and MCG hold the copyright for the Fight Retinal Blindness! real-world data collection tool. DB has received research grants and honoraria from Bayer and Novartis. MCG and HM have received research grants and honoraria from Allergan, Bayer, Novartis and Roche.

Publisher's note Springer Nature remains neutral with regard to jurisdictional claims in published maps and institutional affiliations.

\section{References}

1. Rogers SL, McIntosh RL, Lim L, Mitchell P, Cheung N, Kowalski JW, et al. Natural history of branch retinal vein occlusion: an evidence-based systematic review. Ophthalmology. 2010;117:1094-101.e5.

2. The Branch Vein Occlusion Study Group. Argon laser photocoagulation for macular edema in branch vein occlusion. Am J Ophthalmol. 1984;98:271-82.

3. Park SP, Ahn JK. Changes of aqueous vascular endothelial growth factor and interleukin- 6 after intravitreal triamcinolone for branch retinal vein occlusion. Clin Exp Ophthalmol. 2008; 36:831-5.

4. Scott IU, Ip MS, VanVeldhuisen PC, Oden NL, Blodi BA, Fisher $\mathrm{M}$, et al. A randomized trial comparing the efficacy and safety of intravitreal triamcinolone with standard care to treat vision loss associated with macular Edema secondary to branch retinal vein occlusion: the Standard Care vs Corticosteroid for Retinal Vein Occlusion (SCORE) study report 6. Arch Ophthalmol. 2009;127: 1115-28.

5. Haller JA, Bandello F, Belfort R,Jr, Blumenkranz MS, Gillies M, Heier $\mathrm{J}$, et al. Randomized, sham-controlled trial of dexamethasone intravitreal implant in patients with macular edema due to retinal vein occlusion. Ophthalmology. 2010;117: 1134-46.e3.

6. Haller JA, Bandello F, Belfort R Jr, Blumenkranz MS, Gillies M, Heier J, et al. Dexamethasone intravitreal implant in patients with macular edema related to branch or central retinal vein occlusion twelve-month study results. Ophthalmology. 2011;118:2453-60.

7. The Royal College of Ophthalmologists. Clinical guidelines: retinal vein occlusion (RVO) guidelines. London, UK: The Royal College of Ophthalmologists; 2015. 
8. Campochiaro PA, Heier JS, Feiner L, Gray S, Saroj N, Rundle $\mathrm{AC}$, et al. Ranibizumab for macular edema following branch retinal vein occlusion: six-month primary end point results of a phase III study. Ophthalmology. 2010;117:1102-12.e1.

9. Brown DM, Campochiaro PA, Bhisitkul RB, Ho AC, Gray S, Saroj N, et al. Sustained benefits from ranibizumab for macular edema following branch retinal vein occlusion: 12-month outcomes of a phase III study. Ophthalmology. 2011;118:1594-602.

10. Heier JS, Campochiaro PA, Yau L, Li Z, Saroj N, Rubio RG, et al. Ranibizumab for macular edema due to retinal vein occlusions: long-term follow-up in the HORIZON trial. Ophthalmology. 2012;119:802-9.

11. Campochiaro PA, Sophie R, Pearlman J, Brown DM, Boyer DS, Heier JS, et al. Long-term outcomes in patients with retinal vein occlusion treated with ranibizumab: the RETAIN study. Ophthalmology. 2014;121:209-19.

12. Tadayoni R, Waldstein SM, Boscia F, Gerding H, Pearce I, Priglinger $\mathrm{S}$, et al. Individualized stabilization criteria-driven ranibizumab versus laser in branch retinal vein occlusion: six-month results of BRIGHTER. Ophthalmology. 2016;123: 1332-44.

13. Tadayoni R, Waldstein SM, Boscia F, Gerding H, Gekkieva M, Barnes E, et al. Sustained Benefits of ranibizumab with or without laser in branch retinal vein occlusion: 24-month results of the BRIGHTER study. Ophthalmology. 2017;124:1778-87.

14. Campochiaro PA, Clark WL, Boyer DS, Heier JS, Brown DM, Vitti R, et al. Intravitreal aflibercept for macular edema following branch retinal vein occlusion: the 24-week results of the VIBRANT study. Ophthalmology. 2015;122:538-44.

15. Clark WL, Boyer DS, Heier JS, Brown DM, Haller JA, Vitti R, et al. Intravitreal aflibercept for macular edema following branch retinal vein occlusion: 52-week results of the VIBRANT study. Ophthalmology. 2016;123:330-6.

16. Narayanan R, Panchal B, Das T, Chhablani J, Jalali S, Ali MH. A randomised, double-masked, controlled study of the efficacy and safety of intravitreal bevacizumab versus ranibizumab in the treatment of macular oedema due to branch retinal vein occlusion: MARVEL Report No. 1. Br J Ophthalmol. 2015;99:954-9.

17. Rajagopal R, Shah GK, Blinder KJ, Altaweel M, Eliott D, Wee $R$, et al. Bevacizumab versus ranibizumab in the treatment of macular edema due to retinal vein occlusion: 6-month results of the CRAVE study. Ophthalmic Surg Lasers Imaging Retina. 2015;46:844-50.

18. Schlingemann R. The BRVO Study (conference abstract). 19th European Society of Retinal Specialists (EURETINA) Congress, Paris: European Society of Retinal Specialists; 2019.

19. Hattenbach LO, Feltgen N, Bertelmann T, Schmitz-Valckenberg $\mathrm{S}$, Berk H, Eter N, et al. Head-to-head comparison of ranibizumab PRN versus single-dose dexamethasone for branch retinal vein occlusion (COMRADE-B). Acta Ophthalmol. 2018;96: e10-8.

20. Bandello F, Augustin A, Tufail A, Leaback R. A 12-month, multicenter, parallel group comparison of dexamethasone intravitreal implant versus ranibizumab in branch retinal vein occlusion. Eur J Ophthalmol. 2018;28:697-705.

21. Raszewska-Steglinska M, Gozdek P, Cisiecki S, Michalewska Z, Michalewski J, Nawrocki J. Pars plana vitrectomy with ILM peeling for macular edema secondary to retinal vein occlusion. Eur J Ophthalmol. 2009;19:1055-62.

22. Chung EJ, Lee H, Koh HJ. Arteriovenous crossing sheathotomy versus intravitreal triamcinolone acetonide injection for treatment of macular edema associated with branch retinal vein occlusion. Graefes Arch Clin Exp Ophthalmol. 2008;246:967-74.

23. Kumagai K, Furukawa M, Ogino N, Uemura A, Larson E. Longterm outcomes of vitrectomy with or without arteriovenous sheathotomy in branch retinal vein occlusion. Retina. 2007;27: 49-54.

24. Chen HC, Wiek J, Gupta A, Luckie A, Kohner EM. Effect of isovolaemic haemodilution on visual outcome in branch retinal vein occlusion. Br J Ophthalmol. 1998;82:162-7.

25. Mitry D, Bunce C, Charteris D. Anti-vascular endothelial growth factor for macular oedema secondary to branch retinal vein occlusion. Cochrane Database Syst Rev. 2013:CD009510.

26. Lam FC, Chia SN, Lee RMH. Macular grid laser photocoagulation for branch retinal vein occlusion. Cochrane Database Syst Rev. 2015:CD008732.

27. Ehlers JP, Kim SJ, Yeh S, Thorne JE, Mruthyunjaya P, Schoenberger SD, et al. Therapies for macular edema associated with branch retinal vein occlusion: a report by the american academy of ophthalmology. Ophthalmology. 2017;124:1412-23.

28. Mehta H, Tufail A, Daien V, Lee AY, Nguyen V, Ozturk M, et al. Real-world outcomes in patients with neovascular agerelated macular degeneration treated with intravitreal vascular endothelial growth factor inhibitors. Prog Retin Eye Res. 2018;65:127-46.

29. Black N. Why we need observational studies to evaluate the effectiveness of health care. BMJ. 1996;312:1215-8.

30. National Institute for Health and Care Excellence (NICE). Developing NICE guidelines: the manual. London, UK: National Institute for Health and Care Excellence; 2018.

31. Institute of Health Economics (IHE). Quality appraisal of case series studies checklist. Edmonton, Canada: Institute of Health Economics; 2016.

32. Higgins JP, Thompson SG. Quantifying heterogeneity in a metaanalysis. Stat Med. 2002;21:1539-58.

33. Wan X, Wang W, Liu J, Tong T. Estimating the sample mean and standard deviation from the sample size, median, range and/ or interquartile range. BMC Med Res Methodol. 2014;14:135.

34. Higgins JPT, Green S. Cochrane handbook for systematic reviews of interventions. Chichester, UK: Wiley Online Library; 2008.

35. Furukawa TA, Barbui C, Cipriani A, Brambilla P, Watanabe N. Imputing missing standard deviations in meta-analyses can provide accurate results. J Clin Epidemiol. 2006;59:7-10.

36. Thiessen Philbrook H, Barrowman N, Garg AX. Imputing variance estimates do not alter the conclusions of a meta-analysis with continuous outcomes: a case study of changes in renal function after living kidney donation. J Clin Epidemiol. 2007;60: 228-40.

37. R Core Team. R: a language and environment for statistical computing. R Foundation for Statistical Computing. 2019. https://www.R-project.org/. Accessed 17 Sept 2019.

38. Demir M, Oba E, Gulkilik G, Odabasi M, Ozdal E. Intravitreal bevacizumab for macular edema due to branch retinal vein occlusion: 12-month results. Clin Ophthalmol. 2011;5:745-9.

39. Hoeh AE, Ach T, Schaal KB, Scheuerle AF, Dithmar S. Longterm follow-up of OCT-guided bevacizumab treatment of macular edema due to retinal vein occlusion. Graefes Arch Clin Exp Ophthalmol. 2009;247:1635-41.

40. Kola M, Hacioglu D, Turk A, Erdol H. The effectiveness and reliability of posterior sub-Tenon triamcinolone acetonide injection in branch retinal vein occlusion-related macular edema. Cutan Ocul Toxicol. 2016;35:185-9.

41. Lee K, Jung H, Sohn J. Comparison of injection of intravitreal drugs with standard care in macular edema secondary to branch retinal vein occlusion. Korean J Ophthalmol. 2014;28:19-25.

42. Buyru Ozkurt Y, Akkaya S, Aksoy S, Simsek MH. Comparison of ranibizumab and subthreshold micropulse laser in treatment of macular edema secondary to branch retinal vein occlusion. Eur $\mathbf{J}$ Ophthalmol. 2018;28:690-6.

43. Winterhalter S, Eckert A, Vom Brocke GA, Schneider A, Pohlmann D, Pilger D, et al. Real-life clinical data for 
dexamethasone and ranibizumab in the treatment of branch or central retinal vein occlusion over a period of six months. Graefes Arch Clin Exp Ophthalmol. 2018;256:267-79.

44. Yoon YH, Kim JW, Lee JY, Kim IT, Kang SW, Yu HG, et al. Dexamethasone intravitreal implant for early treatment and retreatment of macular edema related to branch retinal vein occlusion: the multicenter COBALT study. Ophthalmologica. 2018;240:81-9.

45. Chatziralli I, Theodossiadis G, Chatzirallis A, Parikakis E, Mitropoulos P, Theodossiadis P. Ranibizumab for retinal vein occlusion: predictive factors and long-term outcomes in real-life data. Retina. 2018;38:559-68.

46. Siegel RA, Dreznik A, Mimouni K, Bor E, Weinberger D, Bourla DH. Intravitreal bevacizumab treatment for macular edema due to branch retinal vein occlusion in a clinical setting. Curr Eye Res. 2012;37:823-9.

47. Lip PL, Malick H, Damer K, Elsherbiny S, Darrad KM, Mushtaq $\mathrm{B}$, et al. One-year outcome of bevacizumab therapy for chronic macular edema in central and branch retinal vein occlusions in real-world clinical practice in the UK. Clin Ophthalmol. 2015; 9:1779-84.

48. Brynskov T, Kemp H, Sorensen TL. Intravitreal ranibizumab for retinal vein occlusion through 1 year in clinical practice. Retina. 2014;34:1637-43.

49. Braimah IZ, Singh SR, Uplanchiwar B, Mansour AM, Chhablani J. Bevacizumab versus ziv-aflibercept in branch retinal vein occlusion. Indian J Ophthalmol. 2019;67:1109-13.

50. Ozkaya A, Tarakcioglu HN, Tanir I. Ranibizumab versus dexamethasone implant in macular edema secondary to branch retinal vein occlusion: two-year outcomes. Optom Vis Sci. 2018; 95:1149-54.

51. Papadia M, Misteli M, Jeannin B, Herbort CP. The influence of anti-VEGF therapy on present day management of macular edema due to BRVO and CRVO: a longitudinal analysis on visual function, injection time interval and complications. Int Ophthalmol. 2014;34:1193-201.

52. Kornhauser T, Schwartz R, Goldstein M, Neudorfer M, Loewenstein A, Barak A. Bevacizumab treatment of macular edema in CRVO and BRVO: long-term follow-up. (BERVOLT study: Bevacizumab for RVO long-term follow-up). Graefes Arch Clin Exp Ophthalmol. 2016;254:835-44.

53. Wang JK, Su PY, Hsu YR, Chen YJ, Chen FT, Tseng YY. Comparison of the efficacy of intravitreal aflibercept and bevacizumab for macular edema secondary to branch retinal vein occlusion. J Ophthalmol. 2016;2016:8421940.

54. Inagaki K, Ohkoshi K, Ohde S, Deshpande GA, Ebihara N, Murakami A. Subthreshold micropulse photocoagulation for persistent macular edema secondary to branch retinal vein occlusion including best-corrected visual acuity greater than 20/ 40. J Ophthalmol. 2014;2014:251257.

55. Ozkaya A, Celik U, Alkin Z, Faiz Turan M, Yazici AT, Demirok A. Comparison between intravitreal triamcinolone with grid laser photocoagulation versus bevacizumab with grid laser photocoagulation combinations for branch retinal vein occlusion. ISRN Ophthalmol. 2013;2013:141279.

56. Byun YJ, Roh MI, Lee SC, Koh HJ. Intravitreal triamcinolone acetonide versus bevacizumab therapy for macular edema associated with branch retinal vein occlusion. Graefes Arch Clin Exp Ophthalmol. 2010;248:963-71.

57. Hayashi A, Yunoki T, Miyakoshi A, Mitarai K, Fujino T, Yanagisawa S. Intravitreal injection of bevacizumab combined with macular grid laser photocoagulation for macular edema in branch retinal vein occlusion. Jpn J Ophthalmol. 2011;55: 625-31.

58. Tsagkataki M, Papathomas T, Lythgoe D, Kamal A. Twentyfour-month results of intravitreal bevacizumab in macular edema secondary to branch retinal vein occlusion. Semin Ophthalmol. 2015;30:352-9.

59. Hanada N, Iijima H, Sakurada Y, Imasawa M. Recurrence of macular edema associated with branch retinal vein occlusion after intravitreal bevacizumab. Jpn J Ophthalmol. 2012;56:165-74.

60. Lalinska L, Krasny J, Studeny P, Veith M. Results of the first 12 months treatment of macular edema complicating BRVO in patients treated with ranibizumab. Ceska a slovenska oftalmologie: Cas Ceske oftalmologicke spolecnosti a Slovenske oftalmologicke spolecnosti. 2018;74:62-7.

61. Wu L, Arevalo JF, Berrocal MH, Maia M, Roca JA, MoralesCanton V, et al. Comparison of two doses of intravitreal bevacizumab as primary treatment for macular edema secondary to branch retinal vein occlusions: results of the Pan American Collaborative Retina Study Group at 24 months. Retina. 2009; 29:1396-403.

62. Thapa R, Maharjan N, Paudyal G. Intravitreal bevacizumab in macular edema secondary to branch retinal vein occlusion: 12month results. Clin Ophthalmol. 2012;6:1057-62.

63. Rush RB, Simunovic MP, Aragon AV II, Ysasaga JE. Treat-andextend intravitreal bevacizumab for branch retinal vein occlusion. Ophthalmic Surg Lasers Imaging Retina. 2014;45: 212-6.

64. Shiono A, Kogo J, Sasaki H, Yomoda R, Jujo T, Tokuda N, et al. Optical coherence tomography findings as a predictor of clinical course in patients with branch retinal vein occlusion treated with ranibizumab. PLoS ONE. 2018;13:e0199552.

65. Sun Z, Zhou H, Lin B, Jiao X, Luo Y, Zhang F, et al. Efficacy and safety of intravitreal conbercept injections in macular edema secondary to retinal vein occlusion. Retina. 2017;37:1723-30.

66. Noma H, Funatsu H, Mimura T, Shimada K. Comparison of the efficacy of intravitreal triamcinolone acetonide for cystoid macular edema with versus without serous retinal detachment in branch retinal vein occlusion: influence on macular sensitivity and morphology. BMC Ophthalmol. 2012;12:39.

67. Ohashi H, Oh H, Nishiwaki H, Nonaka A, Takagi H. Delayed absorption of macular edema accompanying serous retinal detachment after grid laser treatment in patients with branch retinal vein occlusion. Ophthalmology. 2004;111:2050-6.

68. Bhisitkul RB, Campochiaro PA, Shapiro H, Rubio RG. Predictive value in retinal vein occlusions of early versus late or incomplete ranibizumab response defined by optical coherence tomography. Ophthalmology. 2013;120:1057-63.

69. Folgar FA, Jaffe GJ, Ying G-S, Maguire MG, Toth CA. Comparison of age-related macular degeneration treatments trials research G. Comparison of optical coherence tomography assessments in the comparison of age-related macular degeneration treatments trials. Ophthalmology. 2014;121:1956-65.

70. Pierro L, Zampedri E, Milani P, Gagliardi M, Isola V, Pece A. Spectral domain OCT versus time domain OCT in the evaluation of macular features related to wet age-related macular degeneration. Clin Ophthalmol. 2012;6:219-23.

71. Ahn SJ, Ahn J, Woo SJ, Park KH. Initial dose of three monthly intravitreal injections versus PRN intravitreal injections of bevacizumab for macular edema secondary to branch retinal vein occlusion. Biomed Res Int. 2013;2013:209735.

72. Fileta JB, Scott IU, Flynn HW Jr. Meta-analysis of infectious endophthalmitis after intravitreal injection of anti-vascular endothelial growth factor agents. Ophthalmic Surg Lasers Imaging Retin. 2014;45:143-9.

73. Avery RL, Gordon GM. Systemic safety of prolonged monthly anti-vascular endothelial growth factor therapy for diabetic macular edema: a systematic review and meta-analysis. JAMA Ophthalmol. 2016;134:21-9.

74. Ueta T, Noda Y, Toyama T, Yamaguchi T, Amano S. Systemic vascular safety of ranibizumab for age-related macular 
degeneration: systematic review and meta-analysis of randomized trials. Ophthalmology. 2014;121:2193-203.e1-7.

75. Virgili G, Parravano M, Evans JR, Gordon I, Lucenteforte E. Anti-vascular endothelial growth factor for diabetic macular oedema: a network meta-analysis. Cochrane database Syst Rev. 2017;6:Cd007419.

76. Klein R, Klein BE, Moss SE, Meuer SM. The epidemiology of retinal vein occlusion: the Beaver Dam Eye Study. Trans Am Ophthalmological Soc. 2000;98:133-41. discussion 141-133.

77. Bertelsen M, Linneberg A, Rosenberg T, Christoffersen N, Vorum H, Gade E, et al. Comorbidity in patients with branch retinal vein occlusion: case-control study. BMJ (Clin. Res. ed.) 2012;345:e7885.

78. Ivanovska Adjievska B, Boskurt S, Orovcanec N, DimovskaJordanova $\mathrm{V}$. The outcome of low-frequency intravitreal bevacizumab therapy for macular edema in retinal vein occlusions. Clin Ophthalmol. 2017;11:1183-90.

79. Miwa Y, Muraoka Y, Osaka R, Ooto S, Murakami T, Suzuma K, et al. Ranibizumab for macular edema after branch retinal vein occlusion: one initial injection versus three monthly injections. Retina. 2017;37:702-9.

80. Hayreh SS, Zimmerman B, McCarthy MJ, Podhajsky P. Systemic diseases associated with various types of retinal vein occlusion. Am J Ophthalmol. 2001;131:61-77.

81. Scott IU, Vanveldhuisen PC, Oden NL, Ip MS, Domalpally A, Doft $\mathrm{BH}$, et al. Baseline characteristics and response to treatment of participants with hemiretinal compared with branch retinal or central retinal vein occlusion in the standard care vs corticosteroid for retinal vein occlusion (SCORE) study: SCORE study report 14. Arch Ophthalmol (Chic Ill: 1960). 2012;130: 1517-24.

82. Awdeh RM, Elsing SH, Deramo VA, Stinnett S, Lee PP, Fekrat $\mathrm{S}$. Vision-related quality of life in persons with unilateral branch retinal vein occlusion using the 25 -item National Eye Institute Visual Function Questionnaire. Br J Ophthalmol. 2010;94: 319-23.

83. Guo B, Moga C, Harstall C, Schopflocher D. A principal component analysis is conducted for a case series quality appraisal checklist. J Clin Epidemiol. 2016;69:199-207.e2.

84. Moga C, Guo B, Schopflocher D, Harstall C. Institute of Health Economics (IHE) Methodology papers: development of a quality appraisal tool for case series studies using a modified Delphi technique. Institute of Health Economics (IHE). 2019. https://www.ihe.ca/advanced-search/development-of-a-qua lity-appraisal-tool-for-case-series-studies-using-a-modifieddelphi-technique. Accessed 21 Sept 2019.

85. Rodrigues IA, Sprinkhuizen SM, Barthelmes D, Blumenkranz M, Cheung G, Haller J, et al. Defining a minimum set of standardized patient-centered outcome measures for macular degeneration. Am J Ophthalmol. 2016;168:1-12.

86. Gillies MC, Walton R, Liong J, Arnold JJ, McAllister I, Morlet $\mathrm{N}$, et al. Efficient capture of high-quality data on outcomes of treatment for macular diseases: The fight retinal blindness! Project. Retina. 2014;34:188-95.

87. Ah-Moye S, Zalmay P, Theodorsson M, Harris M, Elhousseini Z, Riaz A, et al. Real-world outcomes in patients with macular oedema secondary to branch retinal vein occlusion receiving anti-VEGF therapy in a UK public hospital setting (conference abstract). 19th European Society of Retina Specialists (EURETINA) Congress 2019, Paris: EURETINA; 2019.

88. Zalmay P, Ah-Moye S, Ang JL, Nguyen V, Elhousseini Z, Asaria R, et al. Real-world outcomes in patients with macular oedema secondary to central retinal vein occlusion receiving anti-VEGF therapy in a UK public hospital setting (conference abstract). 19th European Society of Retina Specialists (EURETINA) Congress 2019, Paris: EURETINA; 2019.
89. Chiang MF, Sommer A, Rich WL, Lum F, Parke DW II. The 2016 American Academy of Ophthalmology IRIS ${ }^{\oplus}$ Registry (Intelligent Research in Sight) Database: characteristics and methods. Ophthalmology. 2018;125:1143-8.

90. Campochiaro PA, Wykoff CC, Singer M, Johnson R, Marcus D, Yau L, et al. Monthly versus as-needed ranibizumab injections in patients with retinal vein occlusion: the SHORE study. Ophthalmology. 2014;121:2432-42.

91. Li F, Sun M, Guo J, Ma A, Zhao B. Comparison of conbercept with ranibizumab for the treatment of macular edema secondary to branch retinal vein occlusion. Curr Eye Res. 2017;42:1174-8.

92. Feltgen N, Hattenbach LO, Bertelmann T, Callizo J, Rehak M, Wolf $\mathrm{A}$, et al. Comparison of ranibizumab versus dexamethasone for macular oedema following retinal vein occlusion: 1-year results of the COMRADE extension study. Acta Ophthalmol. 2018;96:e933-41.

93. Kim M, Jeong S, Sagong M. Efficacy of intravitreal bevacizumab for macular edema following branch retinal vein occlusion stratified by baseline visual acuity. Graefes Arch Clin Exp Ophthalmol. 2017;255:691-7.

94. Son BK, Kwak HW, Kim ES, Yu SY. Comparison of ranibizumab and bevacizumab for macular edema associated with branch retinal vein occlusion. Korean J Ophthalmol. 2017;31: 209-16.

95. Ito Y, Saishin Y, Sawada O, Kakinoki M, Miyake T, Sawada T, et al. Comparison of single injection and three monthly injections of intravitreal bevacizumab for macular edema associated with branch retinal vein occlusion. Clin Ophthalmol. 2015;9:175-80.

96. Kim M, Lee DH, Byeon SH, Koh HJ, Kim SS, Lee SC. Comparison of intravitreal bevacizumab and dexamethasone implant for the treatment of macula oedema associated with branch retinal vein occlusion. Br J Ophthalmol. 2015;99:1271-6.

97. Zhao L, Li B, Feng K, Han L, Ma Z, Liu Y. Bevacizumab treatment for acute branch retinal vein occlusion accompanied by subretinal hemorrhage. Curr Eye Res. 2015;40:752-6.

98. Gokce G, Sobaci G, Durukan AH, Erdurman FC. The comparison of intravitreal triamcinolone and bevacizumab in patients with macular edema secondary to branch retinal vein occlusion. Clin Ophthalmol. 2014;8:355-62.

99. Hikichi T, Higuchi M, Matsushita T, Kosaka S, Matsushita R, Takami K, et al. Two-year outcomes of intravitreal bevacizumab therapy for macular oedema secondary to branch retinal vein occlusion. Br J Ophthalmol. 2014;98:195-9.

100. Istek S, Bursali $\mathrm{O}$, Alagoz G. Intravitreal bevacizumab injection in the treatment of macular edema secondary to branch retinal vein occlusion. Int Eye Sci. 2014;14:979-85.

101. Jaissle GB, Szurman P, Feltgen N, Spitzer B, Pielen A, Rehak M, et al. Predictive factors for functional improvement after intravitreal bevacizumab therapy for macular edema due to branch retinal vein occlusion. Graefes Arch Clin Exp Ophthalmol. 2011;249:183-92.

102. Kim JY, Park SP. Comparison between intravitreal bevacizumab and triamcinolone for macular edema secondary to branch retinal vein occlusion. Korean J Ophthalmol. 2009;23:259-65.

103. Kondo M, Kondo N, Ito Y, Kachi S, Kikuchi M, Yasuma TR, et al. Intravitreal injection of bevacizumab for macular edema secondary to branch retinal vein occlusion:results after 12 months and multiple regression analysis. Retina. 2009;29: 1242-8.

104. Chen $\mathrm{CH}$, Chen YH, Wu PC, Chen YJ, Lee JJ, Liu YC, et al. Treatment of branch retinal vein occlusion induced macular edema in treatment-naive cases with a single intravitreal triamcinolone or bevacizumab injection. Chang Gung Med J. 2010; 33:424-35.

105. Khan M, Wai KM, Silva FQ, Srivastava S, Ehlers JP, Rachitskaya A, et al. Comparison of ranibizumab and bevacizumab for 
macular edema secondary to retinal vein occlusions in routine clinical practice. Ophthalmic Surg Lasers Imaging Retin. 2017; 48:465-72.

106. Lip PL, Malick H, Damer K, Elsherbiny S, Darrad KM, Mushtaq B, et al. One-year outcome of bevacizumab therapy for chronic macular edema in central and branch retinal vein occlusions in real-world clinical practice in the UK. Clin Ophthalmol. 2015;9:1779-84.

107. Houben I, De Zaeytijd J, Deghislage C, Frost NA, Nijs I, Van Calster J. Efficacy of multiple dexamethasone intravitreal implants for refractory retinal vein occlusion-related macular edema and effect of prior vitrectomy. J Ocul Pharm Ther. 2018; 34:710-9.

108. Bezatis A, Spital G, Hohn F, Maier M, Clemens CR, Wachtlin J, et al. Functional and anatomical results after a single intravitreal ozurdex injection in retinal vein occlusion: a 6-month follow-up — the SOLO study. Acta Ophthalmol. 2013;91:e340-7.

109. Lalinska L, Krasny J, Studeny P, Veith M. Results of the first 12 months treatment of macular edema complicating BRVO in patients treated with ranibizumab. Ceska Slov Oftalmol. 2018; 74:62-7.

110. Osaka R, Manabe K, Manabe S, Nakano Y, Takasago Y, Shiragami C, et al. Persistent metamorphopsia associated with branch retinal vein occlusion. PLoS ONE. 2018;13:e0204015.

111. Hasegawa T, Takahashi Y, Maruko I, Kogure A, Iida T. Macular vessel reduction as predictor for recurrence of macular oedema requiring repeat intravitreal ranibizumab injection in eyes with branch retinal vein occlusion. Br J Ophthalmol. 2018;103: 1367-72. 